\title{
Approximately 800-nm-Thick Pinhole-Free Perovskite Films via Facile Solvent Retarding Process for Efficient Planar Solar Cells
}

Zhongcheng Yuan, Yingguo Yang, Zhongwei Wu, Sai Bai, Weidong Xu, Tao Song, Xingyu Gao, Feng Gao and Baoquan Sun

\section{Journal Article}

\section{Tweet}

N.B.: When citing this work, cite the original article.

Original Publication:

Zhongcheng Yuan, Yingguo Yang, Zhongwei Wu, Sai Bai, Weidong Xu, Tao Song, Xingyu Gao, Feng Gao and Baoquan Sun, Approximately 800-nm-Thick Pinhole-Free Perovskite Films via Facile Solvent Retarding Process for Efficient Planar Solar Cells, ACS APPLIED MATERIALS and INTERFACES, 2016. 8(50), pp.34446-34454.

http://dx.doi.org/10.1021/acsami.6b12637

Copyright: American Chemical Society

http://pubs.acs.org/

Postprint available at: Linköping University Electronic Press

http://urn.kb.se/resolve?urn=urn:nbn:se:liu:diva-134078

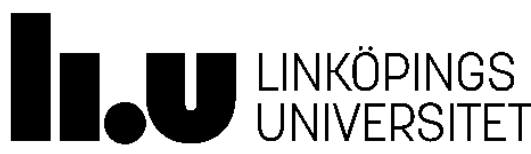




\title{
800-nm-Thick Pinhole-Free Perovskite Films via Facile Solvent Retarding Process for Efficient Planar Solar Cells
}

\author{
Zhongcheng Yuan ${ }^{\dagger, \ddagger}$, Yingguo Yang ${ }^{\S}$, Zhongwei $\mathrm{Wu}^{\dagger}$, Sai $\mathrm{Bai}^{\ddagger}$, Weidong $\mathrm{Xu}^{\dagger}$, Tao Song ${ }^{\dagger}$, \\ Xingyu $\mathrm{Gao}^{\S^{*}}$, Feng $\mathrm{Gao}^{\ddagger *}$ and Baoquan $\mathrm{Sun}^{\dagger *}$ \\ † Jiangsu Key Laboratory for Carbon-Based Functional Materials \& Devices, Institute of Functional Nano \\ \& Soft Materials (FUNSOM), Soochow University, Suzhou, 215123, China \\ ${ }^{\ddagger}$ Department of Physics, Chemistry and Biology (IFM), Linköping University, Linköping, SE-58183 \\ Sweden \\ ${ }^{\S}$ Shanghai Synchrotron Radiation Facility (SSRF), Shanghai Institute of Applied Physics, Key Laboratory \\ of Interfacial Physics and Technology, Shanghai Institute of Applied Physics, Chinese Academy of Sciences, \\ Shanghai, 201800, China
}

Keywords: Perovskite solar cells, solvent retarding, crystallization, components separation, film thickness 


\begin{abstract}
Device performance of organometal halide perovskite solar cells significantly depends on the quality and thickness of perovskite absorber films. However, conventional deposition methods often generate pinholes within $~ 300$-nm-thick perovskite films, which are detrimental to the large area device manufacture. Here we demonstrated a simple solvent retarding process to deposit uniform pinhole free perovskite films with thickness up to $\sim 800 \mathrm{~nm}$. Solvent evaporation during the retarding process facilitated the components separation in the mixed halide perovskite precursors, and hence the final films exhibited pinhole free morphology and large grain sizes. In addition, the increased precursor concentration after solvent-retarding process led to thick perovskite films. Based on the uniform and thick perovskite films prepared by this convenient process, a champion device efficiency up to $16.8 \%$ was achieved. We believe that this simple deposition procedure for high quality perovskite films around micrometer thickness has a great potential in the application of large area perovskite solar cells and other optoelectronic devices.
\end{abstract}




\section{INTRODUCTION}

The emerging solution-processed organometal halide perovskites $\left(\mathrm{CH}_{3} \mathrm{NH}_{3} \mathrm{PbX}, \mathrm{X}=\mathrm{Cl}, \mathrm{Br}\right.$, I or mixed halides) possess excellent optoelectronic properties and have attracted great attention in the research fields of solar cells, lasers, light emitting diodes (LEDs) and photodetectors. ${ }^{1-7}$ The power conversion efficiency (PCE) of perovskite solar cells has rocketed from 3.8\% to a certified efficiency of $22.1 \%$ within a few years, as a result of rapid development of materials, film deposition techniques and interface engineering of device structures. ${ }^{5,8-10}$.

Among all the perovskite films deposition methods, one-step deposition is the most straightforward one that has been widely implemented. However, a critical issue with this technique is that it usually generates pinholes in the perovskite films, resulting in poor film morphology. Especially in thick perovskite films, the pore sizes significantly increase. ${ }^{11}$ For perovskite solar cells, it is desirable to have thick perovskite films with uniform films morphology, so that the devices can tolerate possible thickness fluctuation, and at the same time capture as much incident light as possible. ${ }^{12-13}$

There were several different approaches to obtain perovskite films with high thickness, like increasing the perovskite precursor solution concentration. Unfortunately, these thick films usually showed coarse morphology and poor surface coverage over the substrates. ${ }^{14}$ Thick perovskite films with pinhole-free morphology, to the best of our knowledge, could be accomplished by a 'solvent annealing' process and dual-source thermal evaporation method, which required a careful control of film growth environment and these methods were not suitable for low cost production. ${ }^{13,15}$ In addition, although a thicker layer is desirable for large manufacture, thick-film organic photovoltaics have been found to be generally less efficient than thin-film devices due to the poor mobility and are seldom explored in detail. ${ }^{16}$ Therefore, it is desirable to obtain thick perovskite films through a simple one-step spin-coating process. 
Apart from the thickness, there were several different approaches to tune the morphology of perovskite films. For example, both 'rapid annealing' at high temperatures and 'multi-step annealing' processes could help to improve the film morphology with decreased pinholes. ${ }^{17-18}$ The employment of high boiling point solvents is another approach to decrease the amount of pinholes within the films by slowing down the crystallization process. ${ }^{19}$ Although these approaches help to decrease the amount and sizes of pinholes, a dedicated control of film deposition environment or incorporating additives is usually required to obtain totally pinhole-free films. ${ }^{9,20-24}$.

Here we developed a convenient solvent retarding (SR) method, which successfully generated thick and uniform perovskite films. We conducted a detailed investigation on the influence of the retarded solvent evaporation time (defined as SR time) on mixed halide perovskite film morphology and corresponding device performance. The influence of different SR time on perovskite films absorption and morphology was investigated. Perovskite films that were deposited with a precursor solution of $40 \mathrm{wt} \%$ and $30 \mathrm{~s}$ SR time achieved an 800-nm-thick film and associating device demonstrates a champion PCE of 16.83\%. This simple and convenient one-step spin-coating process to deposit $~ 800$-nm-thick perovskite film shows a great potential in commercial perovskite solar cells production and other solution processed thin film devices.

\section{RESULTS AND DISCUSSION}

\section{Precursor Film Characterization}

Figure 1 shows the procedure of conventional one-step process and the SR process for perovskite film deposition. Both deposition methods, as usual, start with coating the perovskite precursor solution on the substrates. In the SR process, a thick and continuous wetting layer is obtained by spinning the substrates at a low speed (1500 r.p.m.) for a short period (3 s) in order to get rid of redundant precursor solution (Step I). Then the substrates are left on the chuck for a certain SR time (the time range: $15 \mathrm{~s}$ to $120 \mathrm{~s}$ ) to obtain increased precursor concentration during solvent evaporation (Step II, SR process). Subsequently dry perovskite precursor films are accomplished by the second spincoating process with a high rotation speed 
(4000 r.p.m.) (Step III). Finally, the substrates are all thermally annealed in glovebox at $100{ }^{\circ} \mathrm{C}$ for $\sim 45$ $\min$ (Step IV). The film deposited by the conventional one-step procedure without the SR process is referred to as the control film (Con film), which is obtained by a spin-coating process at 4000 r.p.m. for $45 \mathrm{~s}$ (detailed process can be found in the Experimental section).

Before the thermal annealing process, the color of the precursor films deposited with the SR process change dramatically, indicating the formation of crystalized $\mathrm{CH}_{3} \mathrm{NH}_{3} \mathrm{PbI}_{3-\mathrm{x}} \mathrm{Cl}_{\mathrm{x}}$. The ultraviolet visible (UV-Vis) absorption spectra and image of the un-annealed films (the films are prepared with different SR time and stored in glovebox for 10 min after spin-coating) are illustrated in Figure S1. According to the absorption spectra, the Con film shows no absorption peaks in the range of $500 \mathrm{~nm}$ to $850 \mathrm{~nm}$. The color of Con film rarely changes after being stored in glovebox for over $24 \mathrm{~h}$ at room temperature, reserving a transparent yellowish color. This behavior is consistent with previous results that $\mathrm{CH}_{3} \mathrm{NH}_{3} \mathrm{PbI}_{3-\mathrm{x}} \mathrm{Cl}_{\mathrm{x}}$ perovskite crystals could not form without thermal annealing treatment. ${ }^{17}$ While for the perovskite film deposited with the SR process, the films color change from light yellow to dark brown in $\sim 1$ min after the spin-coating process. According to the UV-Vis spectra, the absorption intensity continually increases with prolonged SR time. The peak at $\sim 750 \mathrm{~nm}$ corresponding to the absorption offset of $\mathrm{CH}_{3} \mathrm{NH}_{3} \mathrm{PbI}_{3-\mathrm{x}} \mathrm{Cl}_{\mathrm{x}}$ phase shows up at $60 \mathrm{~s}$ SR time, indicating the formation of $\mathrm{CH}_{3} \mathrm{NH}_{3} \mathrm{PbI}_{3-\mathrm{x}} \mathrm{Cl}_{\mathrm{x}} \cdot{ }^{25}$

The morphology of precursor films plays a crucial role in determining the quality of film after thermal annealing. The scanning electron microscopy (SEM) images of the conventional processed precursor film (Figure 2a) display that the crystals are uniformly distributed with the sizes of $\sim 500 \mathrm{~nm}$, resulting in a mesoporous morphology with pinholes and large gaps. A quick solvent evaporation during high speed spincoating process leads to an abrupt shrinkage of the components, resulting in large strain within the mixture film. ${ }^{26}$ For the precursor films deposited with different SR time (Figure S 2), a continuous change of film morphology is observed. According to the SEM images, with increasing SR time, tiny crystals tend to merge together to form much larger ones. After $30 \mathrm{~s}$ SR process, the precursor crystal sizes increase to $\sim 2 \mu \mathrm{m}$. The crystal sizes continue to grow to over $\sim 5 \mu \mathrm{m}$ when the SR time is extended to $60 \mathrm{~s}$. However, the pronounced 
components aggregation starts to deteriorate the film quality when the SR time is further extended to $120 \mathrm{~s}$, resulting in a poor film morphology with large surface fluctuation. The SEM images reveal that the film morphology of 30 s SR processed film is greatly improved with less pinholes (Figure $2 \mathbf{b}$ ). We believe that two main factors determine the film quality: 1) Since the SR process allows the precursor components to release the strain, dry precursor film with continuous morphology is obtained; 2) The continuing solvent evaporation leads to highly condensed precursor films on the substrates during the SR process.

The SR process plays a key role on the cross-sectional morphology and thickness of the precursor film. According to the cross-sectional SEM image of precursor Con film in Figure $\mathbf{S}$ 3a, these hole form at the interface area between the precursor film and the substrate. We believe that the holes result in poor contact at the interface, further leading to pinholes growing in the film after annealing process. The Con film displays a uniform film with $\sim 600 \mathrm{~nm}$ thickness, while the SR processed films all show much enhanced film thicknesses. Film processed with 15 s SR (Figure S 3b) gives uniform cross-section with negligible amounts of holes at the interfaces area and an improved contact as well. However, a bilayer structure shows up in the precursor film processed with $30 \mathrm{~s}$ SR process and a much enhanced film thickness $\sim 1.3 \mu \mathrm{m}$ is obtained (Figure S 3c). When the SR time is further prolonged to $60 \mathrm{~s}$, a $\sim 2 \mu \mathrm{m}$ thick film and hollow structure is formed (Figure S 3d). The hollow structure might be ascribed to the continuous solvent evaporation that leads to the film shrinkage after film deposition.

\section{Annealed Perovskite Film Characterization}

The morphology of films processed with different SR time after the thermal annealing process change dramatically, as the SEM images and atomic force microscope (AFM) images show in Figure S4 and S5. It turns out that the perovskite domain sizes increase with increasing SR time. When the SR process time is extended to 120 s, poor film morphology with large surface fluctuation was observed. According to the average roughness of different films that listed in Table S1, the average roughness of $120 \mathrm{~s}$ SR process is $\sim 79.1 \mathrm{~nm}$, which is much larger than the conventional processed film $(26.8 \mathrm{~nm})$ and $30 \mathrm{~s}$ SR processed film (36.2 nm). This high roughness is caused by precursor components aggregation, which leads to large film 
fluctuation and incontinuity. Compared with the SEM image of the Con film (Figure 2c), 30 s SR processed perovskite film (Figure 2d) exhibits a more continuous morphology. Both the density and sizes of pinholes lying in the surface decrease dramatically. According to the high resolution SEM image shown in Figure 2d, the grain boundaries are merged together and the grain sizes of the perovskite films increase obviously. For the Con film, the long distance between precursor crystals before the thermal annealing process, volume shrinkage and large strain within the film during the thermal annealing process further contribute to a deteriorated film morphology.

After thermal annealing process, as shown in the cross-sectional SEM image in Figure $\mathbf{3 b}$, perovskite film prepared with $30 \mathrm{~s}$ SR process demonstrates a uniform film with a thickness of $\sim 800 \mathrm{~nm}$, while the Con film (Figure 3a) exhibits an average thickness of $\sim 300 \mathrm{~nm}$. According to the precursor film thickness values in Figure S3, the film thickness shrinkage ratio before and after thermal annealing treatment is $~ 50 \%$ (300 $\mathrm{nm} / 600 \mathrm{~nm}$ ) in the Con film. However, the film thickness shrinkage ratio for the film prepared with $30 \mathrm{~s}$ SR process is only $\sim 38 \%(500 \mathrm{~nm} / 1300 \mathrm{~nm})$ after thermal annealing.

Previous reports demonstrated that precursor complexes of $\mathrm{PbI}_{2}, \mathrm{CH}_{3} \mathrm{NH}_{3} \mathrm{I}$ and $\mathrm{CH}_{3} \mathrm{NH}_{3} \mathrm{Cl}$ were formed when dissolving the $\mathrm{PbCl}_{2}$ and $\mathrm{CH}_{3} \mathrm{NH}_{3} \mathrm{I}$ powder in $\mathrm{N}, \mathrm{N}$-dimethylformamide (DMF) solvent. ${ }^{27}$ During the film deposition process, the fast solvent evaporation in the Con film results in a uniform distribution of I and $\mathrm{Cl}$ anions in the precursor films, and causes almost half film thickness shrinkage after the thermal annealing. While in SR processed films, the wet precursor film offers an environment that facilitates the diffusion of $\mathrm{Cl}$ and I components during the SR process and results in the components separation between $\mathrm{Cl}$ rich domains and I rich ones. The schematic image of components separation is depicted in Figure 3c. During the SR process (Step I), the concentration of precursor film increases with successive solvent evaporation. I rich domains tend to appear at the interface region near the $\mathrm{TiO}_{\mathrm{x}}$ surface because of their relatively low solubility in DMF. Residual solution containing high concentration of $\mathrm{Cl}$ components is preserved on top of the I rich domains. ${ }^{28-29}$ After the SR process, a secondary spin-coating process helps to partially remove the $\mathrm{Cl}$ rich precursor solution on top of the film. Decreased amount of $\mathrm{Cl}$ components in 
the precursor film minimizes the thickness change of the precursor film during thermal annealing treatment, agreeing very well with our observations that demonstrated above. A recent work by Pool VL et al also supported this separation between $\mathrm{Cl}$ and I components. ${ }^{28}$ Their results proved that mixed halide perovskite precursor film contained less $\mathrm{Cl}$ than corresponding precursor solution. During spin-coating process, even a quick solvent evaporation would lead to the precipitation of I rich domain on the substrate, while $\mathrm{Cl}$ rich solution preserved at the upper part of the precursor film was spread away. This components separation can be distinguished from the cross-sectional image in Figure S 3c, where a bilayer structure shows up after 30 s SR process. The pre-formed I rich domains show firm contact with the substrates, which helps to form continuous film and improved adhesion between perovskite and $\mathrm{TiO}_{\mathrm{x}}$ substrates. While the $\mathrm{Cl}$ components remain at the upper part of the precursor film, cover the whole film. In addition, the component separation also favors the release of $\mathrm{CH}_{3} \mathrm{NH}_{3} \mathrm{Cl}$ during thermal annealing process. This conclusion well explained that preparing a thick perovskite film with conventional method was difficult since thick perovskite film always hindered the release of uniformly distributed $\mathrm{CH}_{3} \mathrm{NH}_{3} \mathrm{Cl}$ within the film. In addition, a unique combination of two factors, i.e. the release of film strain and $\mathrm{I} / \mathrm{Cl}$ component separation, contribute to uniform film morphology. At the same time, the condensed precursor concentration during SR process leads to much improved film thickness.

The optical properties of different SR time processed perovskite film after thermal annealing process, UVVis absorption spectra and steady-state photoluminescence (PL) spectra are conducted and depicted in Figure 3d. The SR processed films show improved light harvesting capability from $\sim 500 \mathrm{~nm}$ to $\sim 790 \mathrm{~nm}$, which is mainly ascribed to the increased film thicknesses. ${ }^{13}$ In addition, there are obvious red shifts of the UV-Vis absorption edges and steady-state PL peaks position for the films processed with SR process, which we believe, is related to the increased grains size. ${ }^{13,30-31}$ Besides, the steady-state PL spectra of SR processed perovskite films demonstrate narrow PL full width at half maximum (FWHM). The FWHM of perovskite film after $30 \mathrm{~s}$ and $60 \mathrm{~s}$ SR process are $\sim 10 \mathrm{~nm}$ narrower than the Con film. The narrower FWHM might be ascribed to the decreased amount of in-gap defect states. Previous results demonstrated that high 
recombination rate generally occurred at crystal domain boundary within perovskite films. ${ }^{32}$ The increased grain sizes and merged crystal domain boundary dramatically diminished the boundary area, further suppressing the amount of defect states. ${ }^{33}$

Time-correlated single-photon counting (TCSPC) is a useful method to characterize photo-induced dynamical processes in perovskite film. The PL decay, which contained a fast decay and a slow one, is fitted by a bi-exponential decay function and shown in Figure 3e. According to the fitting parameters in Table S2, the average PL lifetime of control film is $134.5 \mathrm{~ns}$ and the slow decay fraction is $45.2 \%$. With SR time increased, the average PL lifetime grow dramatically. For $30 \mathrm{~s}$ SR processed film, the averaged lifetime is greatly improved to more than 6 times higher than the control film, reaching 837.3 ns. In addition, all the SR processed perovskite films show much larger fraction of slow decay, which proves that much decreased amount of recombination occurs at trap states and defects in SR processed perovskite film. The improved film quality results in reduced defect states in the film. This result complies well with the red shift of absorption and the narrowing of PL peaks, which are ascribed to enlarged grain size and merged boundaries.

The effect of the SR process on film crystallization quality was further investigated by the X-ray diffraction (XRD) measurements (Figure S5). All films show strong peaks at $14.1^{\circ}, 28.5^{\circ}$ and $31.9^{\circ}$, corresponding to the (110), (220), and (310) crystal planes of mixed-halide perovskite with an orthorhombic crystal structure, respectively. ${ }^{34}$ The dramatically enhanced peak at (110) plane of the film prepared with $30 \mathrm{~s}$ SR process proves a better crystallization and larger crystal size. 2D grazing incidence X-ray diffraction (GIXRD) is performed to detect the film crystal orientation. According to the GIXRD patterns depicted in Figure 4a and $\mathbf{4 b}$, similar diffraction rings with spotty patterns indicate highly textured perovskite crystal domains. However, their integrated intensity plots of two pattern along the (110) and (220) diffraction rings (Figure 4c and 4d) reveal that $30 \mathrm{~s}$ SR processed film exhibits much higher preferential in-plane orientation than the Con one. The enhancement of the peak height agrees with improved perovskite film crystal quality in SR process. 
To further explore the influence of prolonged solvent evaporation time on film morphology, we examine an extreme case, where the perovskite film was prepared by spin-coating on $\mathrm{TiO}_{\mathrm{x}}$ substrate for $3 \mathrm{~s}$ and then left to dry naturally in the glass petri dish in nitrogen atmosphere. As the SEM image of the perovskite film (after thermal annealing) shown in Figure S7, slow solvent evaporation results in very poor morphology. The film exhibits large amounts of pinholes with sizes ranging from $100 \mathrm{~nm}$ to $3 \mu \mathrm{m}$. Due to the remarkable crystallization property, perovskite components tend to aggregate during the slow solvent evaporation process. These results clearly illustrated the importance of controlling the solvent evaporation rate and its effect to the final film morphology.

\section{Photovoltaics Performance}

Perovskite solar cells were fabricated with the films prepared by either conventional method or SR procedure. Corresponding device geometry (in Figure 5a) was conventional planar perovskite solar cell. Low temperature $\left(150{ }^{\circ} \mathrm{C}\right)$ solution processed $\mathrm{TiO}_{\mathrm{x}}$ film and doped 2,2',7,7'-Tetrakis-(N,N-di-pmethoxyphenylamino)-9,9'-spirobifluorene (Spiro-OMeTAD) acted as electron transporting layer (ETL) and hole transporting layer (HTL), respectively (details were included in Experimental section). ${ }^{35}$

All device PCEs were measured under simulated light with an intensity of $100 \mathrm{~mW} / \mathrm{cm}^{2}$, and associating current versus voltage (J-V) curves were depicted in Figure 5b. For the devices based on the SR process, the lengths of the retarding time play key roles on device performance. Corresponding photovoltaics output parameters are summarized in Table 1. The film fabricated with SR time of $15 \mathrm{~s}$ displays a moderate effect on device performance. When the SR time is increased to $30 \mathrm{~s}$, an average PCE of $16.28 \%$ is obtained. Compared with conventional device, the average $\mathrm{J}_{\mathrm{sc}}$ value increases from $19.84 \mathrm{~mA} \cdot \mathrm{cm}^{-2}$ to 22.04 $\mathrm{mA} \cdot \mathrm{cm}^{-2}$, demonstrating $10 \%$ enhancement. When the SR time is prolonged to $60 \mathrm{~s}$, the PCE slightly drops to $15.51 \%$. The device based on 120 s SR processed film gives a poor efficiency of $12.02 \%$, which is mainly caused by the deceased FF and open circuit voltage $\left(V_{\text {oc }}\right)$. As discussed above, $120 \mathrm{~s}$ SR process leads to large surface fluctuation on film morphology and deteriorates the performance of devices. Here the 
device prepared with 30 s SR process demonstrates a champion PCE of $16.83 \%$ (Figure 5c), with a $V_{\text {oc }}$ of $1.02 \mathrm{~V}$, a $\mathrm{J}_{\mathrm{sc}}$ of $22.30 \mathrm{~mA} \cdot \mathrm{cm}^{-2}$ and a FF of 0.74 , showing more than $20 \%$ enhancement over the control devices. The publications regarding to perovskite films with thickness over $500 \mathrm{~nm}$ are summarized and displayed in Table S3. As far as we know, this is the highest device PCE obtained ever based on perovskite film with thickness over $600 \mathrm{~nm}$. The enhanced $\mathrm{J}_{\mathrm{sc}}$ is attributed to the increased film thickness, while the pinhole free film morphology and decreased grain boundary area lead to much improved $\mathrm{FF}$ and $\mathrm{V}_{\text {oc}}$. The external quantum efficiency (EQE) spectra of devices (Figure 5d), shows that the device based on $30 \mathrm{~s}$ SR perovskite films gives an entire range enhancement from $400 \mathrm{~nm}$ to $780 \mathrm{~nm}$. However, according to the UV-Vis absorption spectra (Figure 3d), there is rare absorption enhancement at short wavelength region (300-500 nm) even with film prepared by 120 s SR time. This implies that the charge carriers generate from high energy photons are mainly absorbed within the film near the $\mathrm{TiO}_{\mathrm{x}}$ interface (as shown the schematic image in Figure S 8). In this case, there is a larger density of charge carrier distribution near the interface. The recombination happens in this region played a critical role on device performance. ${ }^{36}$ Better contact and decreased amount of interface defects greatly hinder the trap-assisted recombination, which leads to higher EQE values at short wavelength region of SR processed device. In addition, the enhancement around 780 nm agrees well with the enlarged absorption range of UV-Vis absorption spectra. Apart from the enhanced device performance, we observe a higher reproducibility of SR processed perovskite device than the control ones. As the histogram of corresponding devices illustrated in Figure 5e, devices fabricated with the $30 \mathrm{~s}$ SR process yield much narrower PCE distribution.

One of the anomalous features in perovskite photovoltaics device was the hysteresis phenomenon that occurred when measuring device $\mathrm{J}-\mathrm{V}$ performance with different scanning conditions. This hysteresis became severe in planar structured device, especially in devices based on $\mathrm{TiO}_{2}$ compact film. ${ }^{37}$ The reason of hysteresis phenomenon in perovskite device was ascribed to the ion migration, boundary defects, and unbalanced charge carrier transport etc. ${ }^{37-41}$ The hysteresis result (Figure $5 \mathbf{f}$ and Table S4) of devices based on Con film and 30 s SR film were obtained with forward (from bias to short circuit) and reverse scanning 
(from short circuit to bias). Hysteresis in the latter device is much weaker than that in control one. For both devices, the $\mathrm{J}_{\mathrm{sc}}$ values varied slightly with different scanning directions. However, the differences in $\mathrm{V}_{\text {oc }}$ and FF of conventionally prepared device are significant between forward and back scanning. The inferior film morphology and poor contact at the interface leads to the formation of large amounts of trap states near the interfacial area and film surface, which is consistent with the previous report. ${ }^{42}$ In contrast, the 30 s SR processed film displays much better contact with the substrates, which improves adhesion between perovskite and $\mathrm{TiO}_{\mathrm{x}}$ substrates. In addition, the enlarged crystal sizes and crystalline quality, less boundary defects within SR processed perovskite film all contribute to the reduced device hysteresis. ${ }^{32,41,43-46}$

By further increasing the concentration of perovskite precursor to $50 \mathrm{wt} \%$, we achieved an average film thickness over $1.2 \mu \mathrm{m}$ with $30 \mathrm{~s}$ SR process. This is the highest perovskite film thickness obtained with mixed halide perovskite precursor solution with spincoating process. As the cross-sectional SEM image of the device depicted in Figure S 9a, a condensed and continuous film is formed. The J-V curve of the device based on this film is depicted in Figure S 9b, demonstrating a PCE of 14.53\%, a $\mathrm{J}_{\mathrm{sc}}$ of $20.72 \mathrm{mAcm}^{-2}$, a $\mathrm{V}_{\text {oc }}$ of $0.99 \mathrm{~V}$ and a FF of 0.69 . For future commercialization of perovskite solar cells, it is desirable to have thick perovskite films with uniform morphology so that the devices can tolerate possible thickness fluctuation during large-scale production. However, the high concentration of $50 \mathrm{wt} \%$ will lead to fluctuations on film roughness due to much enhanced viscosity of wet film after SR process. Further work is under way to solve the film fluctuation issue.

\section{CONCLUSIONS}

In summary, we demonstrated that the simple SR process dramatically improved perovskite film quality and increased the film thickness to $\sim 800 \mathrm{~nm}$. The thick and pinhole free perovskite film ensur a good light harvesting, and associated device yields a highest PCE of $16.83 \%$ with decreased hysteresis. With a high concentration perovskite precursor (50 wt \%), film thickness up to $1.2 \mu \mathrm{m}$ is obtained. No additives or extra solvent are required in the SR film deposition process. The combined effects of released film strain and I/Cl components separation lead to large grain size and high film uniformity, while condensed precursor 
concentration during SR process result in improved film thickness. We believe that this convenient method for perovskite film deposition will be a promising approach to fabricate large scale solar cells and other perovskite optoelectronics.

\section{EXPERIMENTAL SECTION}

\section{Materials and Synthesis:}

ITO substrates were all purchased from Shenzhen Nanbo Ltd. Titanium isopropoxide (97\%), methylamine $\left(\mathrm{CH}_{3} \mathrm{NH}_{2}\right)$ and hydrogen iodide (HI) were purchased from Sigma Aldrich. 2-isopropanol (HPLC, 99.9\%), ethanol (HPLC, 99\%), lead chloride ( $\left.\mathrm{PbCl}_{2}, 99.99 \%\right)$, N, N-Dimethylformamide (DMF, 99.9\%) were purchased from Alfa Aesar. All the materials were used as received without further purification. Methylammonium iodide $\left(\mathrm{CH}_{3} \mathrm{NH}_{3} \mathrm{I}\right)$ was synthesized by following reported method ${ }^{47}$ and purified with ethanol twice. $\mathrm{CH}_{3} \mathrm{NH}_{3} \mathrm{I}$ crystals was dried at $45^{\circ} \mathrm{C}$ in vacuum for $48 \mathrm{~h}$ before usage. The precursor solution of mixed halide perovskite with a concentration of $40 \mathrm{wt} \%$ and $50 \mathrm{wt} \%$ are prepared by mixing $\mathrm{CH}_{3} \mathrm{NH}_{3} \mathrm{I}$ with $\mathrm{PbCl}_{2}$ powder with a molar ration of $1: 3$ in DMF. The mixture solution was stirred at $70{ }^{\circ} \mathrm{C}$ over $8 \mathrm{~h}$ and filtered with a $0.45 \mu \mathrm{m}$ filter before film preparation.

\section{Device fabrication process:}

All the ITO substrates were thoroughly cleaned with acetone, ethanol and distilled water for sequence in ultrasonic bath for $30 \mathrm{~min}$. The substrates were then dried at high-speed nitrogen flow prior to 20 min of UV-ozone treatment to eliminate the organic residues. The fabrication process of two layers of $\mathrm{TiO}_{\mathrm{x}}$ layer

( 100 nm) was described in previous publication. ${ }^{35,48}$ For control devices, perovskite films were spin-coated on the $\mathrm{TiO}_{\mathrm{x}}$ substrates in glovebox at 3500 r.p.m for 40 s. For SR devices, the substrates that covered with perovskite precursor were first spin-coated at 1500 r.m.p. for 3 s. Then the devices were left still on the holder of spin-coater for 15-120 s to allow solvent evaporation. After this process, all the substrates were spin-coated at 3500 r.p.m. for another $40 \mathrm{~s}$ to ensure the film were totally dried. All the perovskite films were annealed at $95{ }^{\circ} \mathrm{C}$ in ambient condition until the color is fully changed to dark brown. HTLs were 
prepared by spic-coating corresponding solution at 3000 r.p.m. for 30 s onto perovskite film. $28.5 \mu \mathrm{L} 4$-tertbutylpyridine (TBP) and $17.5 \mu \mathrm{L}$ lithium-bis (trifluoromethanesulfonyl) imide (Li-TFSI) $(520 \mathrm{mg} / \mathrm{mL}$ in acetonitrile) were mixed in $1 \mathrm{ml}$ Spiro-OMeTAD chlorobenzene solution with a concentration $80 \mathrm{mg} / \mathrm{mL} .{ }^{49}$ Oxygen doping process towards Spiro-OMeTAD in ambient condition was need prior to electrode deposition. The device fabrication processes were finished by depositing $150 \mathrm{~nm} \mathrm{Ag}$ film electrode on top of Spiro-OMeTAD. The device working area is $0.0725 \mathrm{~cm}^{2}$.

\section{Characterization and measurements:}

PCE and EQE spectra data were collected by a Keithley 2612. Perovskite devices were tested in a sealed holder filled with nitrogen under a simulated Xenon light source (intensity of $100 \mathrm{~mW} / \mathrm{cm}^{2}$, calibrated by silicon solar cell 91150 before test). EQE spectra was measured with a steady-state xenon light source and SEM images were obtained by FEI (Quanta 200 FEG) scanning electron microscopy. For the optical measurements of precursor film, all the precursor samples are covered with a $200 \mathrm{~nm}$ layer of polymethyl methacrylate (PMMA) and 200 um glass to protect the surface from moisture corrosion due to the sensitivity of the un-annealed film samples. UV-Vis absorption spectra is obtained with PerkinElmer Lambda 700. Steady state PL spectra and TCSPC characterization results were obtained with a $485 \mathrm{~nm}$ laser and an Andor spectrometer. The XRD spectrum of perovskite film was performed using a PANAlytical Empyrean system. GIXRD pattern and integrated intensity plots were acquired form BL14B1 beamline station of Shanghai Synchrotron Radiation Facility (SSRF) with the wavelength of $0.124 \mathrm{~nm}$. The two dimensional GIXRD (2D-GIXRD) patterns were acquired by a MarCCD mounted vertically at a distance around $246 \mathrm{~mm}$ from the sample with the exposure times less than $50 \mathrm{sec}$, and the grazing incidence angle of X-ray was $0.2^{\circ}$ with respect to the surface plane. ${ }^{50}$ 


\section{ASSOCIATED CONTENT}

\section{Supporting information}

The Supporting Information is available free of charge on the ACS Publications website.

The UV-Vis absorption, digital photography and SEM images of perovskite precursor films with different SR time; SEM, AFM images and XRD pattern of perovskite films after thermal annealing, the schematic images of charge carrier distribution; the performance of device based on $1200 \mathrm{~nm}$ thickness perovskite film; average roughness value and TCSPC characterization of the perovskite films processed with different condition; Photovoltaic parameters of perovskite devices based on films with thicknesses over $500 \mathrm{~nm}$ in literature; J-V statistics of the devices with different condition scanned with different direction with bias step of $100 \mathrm{mV}$

\section{AUTHOR INFORMATION}

\section{Corresponding Authors}

*Email: bqsun@suda.edu.cn

* Email: fenga@ifm.liu.se

*Email: gaoxingyu@sinap.ac

Notes

The authors declare no competing financial interest. 


\section{ACKNOWLEDGMENTS}

Thanks for the GIXRD measurements at BL14B beamline station of Shanghai Synchrotron Radiation

Facility. Thanks for Mr. Chuanfei Wang’s help on steady-state PL measurements and Mr Deping Qian’s help on the synthesis of $\mathrm{CH}_{3} \mathrm{NH}_{3} \mathrm{I}$. This work was supported by the National Natural Science Foundation of China (61176057, 91123005, 61211130358), the Priority Academic Program Development of Jiangsu Higher Education Institutions, Natural Science Foundation of Jiangsu Province of China (BK20130310), Collaborative Innovation Center of Suzhou Nano Science and Technology, the Swedish Research Councils (VR, grant No. 330-2014-6433 and FORMAS, grant No. 942-2015-1253), the Carl Tryggers Stiftelse, and the European Commission Marie Skłodowska-Curie Actions (grant Nos. 691210 and INCA 600398). Z.Y. also thanks the financial support from the China Scholarship Council. 


\section{REFERENCES}

1. Stranks, S. D.; Snaith, H. J. Metal-Halide Perovskites for Photovoltaic and Light-Emitting Devices. Nat. Nanotechnol. 2015, 10, 391-402.

2. Wang, J.; Wang, N.; Jin, Y.; Si, J.; Tan, Z.-K.; Du, H.; Cheng, L.; Dai, X.; Bai, S.; He, H.; Ye, Z.; Lai, M. L.; Friend, R. H.; Huang, W. Interfacial Control Toward Efficient and Low-Voltage Perovskite LightEmitting Diodes. Adv. Mater. 2015, 27, 2311-2316.

3. Hoye, R. L. Z.; Chua, M. R.; Musselman, K. P.; Li, G.; Lai, M.-L.; Tan, Z.-K.; Greenham, N. C.; MacManus-Driscoll, J. L.; Friend, R. H.; Credgington, D. Enhanced Performance in Fluorene-Free Organometal Halide Perovskite Light-Emitting Diodes using Tunable, Low Electron Affinity Oxide Electron Injectors. Adv. Mater. 2015, 27, 1414-1419.

4. Xing, G.; Mathews, N.; Lim, S. S.; Yantara, N.; Liu, X.; Sabba, D.; Grätzel, M.; Mhaisalkar, S.; Sum, T. C. Low-Temperature Solution-Processed Wavelength-Tunable Perovskites for Lasing. Nat. Mater. 2014, 13, 476-480.

5. Bi, D.; Tress, W.; Dar, M. I.; Gao, P.; Luo, J.; Renevier, C.; Schenk, K.; Abate, A.; Giordano, F.; Correa Baena, J.-P.; Decoppet, J.-D.; Zakeeruddin, S. M.; Nazeeruddin, M. K.; Grätzel, M.; Hagfeldt, A. Efficient Luminescent Solar Cells Based on Tailored Mixed-Cation Perovskites. Sci. Adv. 2016, 2, e1501170.

6. Wu, Z.; Bai, S.; Xiang, J.; Yuan, Z.; Yang, Y.; Cui, W.; Gao, X.; Liu, Z.; Jin, Y.; Sun, B. Efficient Planar Heterojunction Perovskite Solar Cells Employing Graphene Oxide as Hole Conductor. Nanoscale 2014, 6, 10505-10510.

7. Bai, S.; Yuan, Z.; Gao, F. Colloidal Metal Halide Perovskite Nanocrystals: Synthesis, Characterization, and Applications. J. Mater. Chem. C 2016, 4, 3898-3904.

8. Bai, S.; Wu, Z.; Wu, X.; Jin, Y.; Zhao, N.; Chen, Z.; Mei, Q.; Wang, X.; Ye, Z.; Song, T., HighPerformance Planar Heterojunction Perovskite Solar Cells: Preserving Long Charge Carrier Diffusion Lengths and Interfacial Engineering. Nano Res. 2014, 7, 1749-1758. 
9. Zhou, H.; Chen, Q.; Li, G.; Luo, S.; Song, T.-b.; Duan, H.-S.; Hong, Z.; You, J.; Liu, Y.; Yang, Y. Interface Engineering of Highly Efficient Perovskite Solar Cells. Science 2014, 345, 542-546.

10. NREL Efficiency Chart. http://www.nrel.gov/ncpv/images/efficiency_chart.jpg (accessed July 8, 2016). 11. Eperon, G. E.; Burlakov, V. M.; Docampo, P.; Goriely, A.; Snaith, H. J. Morphological Control for High Performance, Solution-Processed Planar Heterojunction Perovskite Solar Cells. Adv. Funct. Mater. 2014, 24, 151-157.

12. Mei, A.; Li, X.; Liu, L.; Ku, Z.; Liu, T.; Rong, Y.; Xu, M.; Hu, M.; Chen, J.; Yang, Y.; Grätzel, M.; Han, H. A Hole-Conductor-Free, Fully Printable Mesoscopic Perovskite Solar Cell with High Stability. Science 2014, 345, 295-298.

13. Xiao, Z.; Dong, Q.; Bi, C.; Shao, Y.; Yuan, Y.; Huang, J. Solvent Annealing of Perovskite-Induced Crystal Growth for Photovoltaic-Device Efficiency Enhancement. Adv. Mater. 2014, 26, 6503-6509.

14. Conings, B.; Baeten, L.; De Dobbelaere, C.; D'Haen, J.; Manca, J.; Boyen, H.-G. Perovskite-Based Hybrid Solar Cells Exceeding 10\% Efficiency with High Reproducibility Using a Thin Film Sandwich Approach. Adv. Mater. 2014, 26, 2041-2046.

15. Momblona, C.; Malinkiewicz, O.; Roldán-Carmona, C.; Soriano, A.; Gil-Escrig, L.; Bandiello, E.; Scheepers, M.; Edri, E.; Bolink, H. J. Efficient Methylammonium Lead Iodide Perovskite Solar Cells With Active Layers From 300 to 900 nm. APL Mater. 2014, 2, 081504.

16. Li, G.; Shrotriya, V.; Yao, Y.; Yang, Y. Investigation of Annealing Effects and Film Thickness Dependence of Polymer Solar Cells Based on Poly(3-hexylthiophene). J. Appl. Phys. 2005, 98, 043704.

17. Dualeh, A.; Tétreault, N.; Moehl, T.; Gao, P.; Nazeeruddin, M. K.; Grätzel, M. Effect of Annealing Temperature on Film Morphology of Organic-Inorganic Hybrid Pervoskite Solid-State Solar Cells. Adv. Funct. Mater. 2014, 24, 3250-3258.

18. Saliba, M.; Tan, K. W.; Sai, H.; Moore, D. T.; Scott, T.; Zhang, W.; Estroff, L. A.; Wiesner, U.; Snaith, H. J. Influence of Thermal Processing Protocol upon the Crystallization and Photovoltaic Performance of Organic-Inorganic Lead Trihalide Perovskites. J. Phys. Chem. C 2014, 118, 17171-17177. 
19. Kim, H.-B.; Choi, H.; Jeong, J.; Kim, S.; Walker, B.; Song, S.; Kim, J. Y. Mixed Solvents for the Optimization of Morphology in Solution-Processed, Inverted-Type Perovskite/Fullerene Hybrid Solar Cells. Nanoscale 2014, 6, 6679-6683.

20. Qiu, W.; Merckx, T.; Jaysankar, M.; Masse de la Huerta, C.; Rakocevic, L.; Zhang, W.; Paetzold, U. W.; Gehlhaar, R.; Froyen, L.; Poortmans, J.; Cheyns, D.; Snaith, H. J.; Heremans, P. Pinhole-Free Perovskite Films for Efficient Solar Modules. Energy Environ. Sci. 2016, 9, 484-489.

21. Zhang, W.; Pathak, S.; Sakai, N.; Stergiopoulos, T.; Nayak, P. K.; Noel, N. K.; Haghighirad, A. A.; Burlakov, V. M.; deQuilettes, D. W.; Sadhanala, A.; Li, W.; Wang, L.; Ginger, D. S.; Friend, R. H.; Snaith, H. J. Enhanced Optoelectronic Quality of Perovskite Thin Films with Hypophosphorous Acid for Planar Heterojunction Solar Cells. Nat. Commun. 2015, 6, 10030.

22. Marco, N. D.; Zhou, H.; Chen, Q.; Sun, P.; Liu, Z.; Meng, L.; Yao, E.-P.; Liu, Y.; Schiffer, A.; Yang, Y. Guanidinium: A Route to Enhanced Carrier Lifetime and Open-Circuit Voltage in Hybrid Perovskite Solar Cells. Nano Lett. 2016, 16, 1009-1016.

23. Gong, X.; Li, M.; Shi, X.-B.; Ma, H.; Wang, Z.-K.; Liao, L.-S. Controllable Perovskite Crystallization by Water Additive for High-Performance Solar Cells. Adv. Funct. Mater. 2015, 25, 6671-6678.

24. Zhang, W.; Saliba, M.; Moore, D. T.; Pathak, S. K.; Hörantner, M. T.; Stergiopoulos, T.; Stranks, S. D.; Eperon, G. E.; Alexander-Webber, J. A.; Abate, A.; Sadhanala, A.; Yao, S.; Chen, Y.; Friend, R. H.; Estroff, L. A.; Wiesner, U.; Snaith, H. J. Ultrasmooth Organic-Inorganic Perovskite Thin-Film Formation and Crystallization for Efficient Planar Heterojunction Solar Cells. Nat. Commun. 2015, 6, 6142.

25. Unger, E. L.; Bowring, A. R.; Tassone, C. J.; Pool, V. L.; Gold-Parker, A.; Cheacharoen, R.; Stone, K. H.; Hoke, E. T.; Toney, M. F.; McGehee, M. D. Chloride in Lead Chloride-Derived Organo-Metal Halides for Perovskite-Absorber Solar Cells. Chem. Mater. 2014, 26, 7158-7165.

26. Zhao, Y.; Zhu, K. $\mathrm{CH}_{3} \mathrm{NH}_{3} \mathrm{Cl}$-Assisted One-Step Solution Growth of $\mathrm{CH}_{3} \mathrm{NH}_{3} \mathrm{PbI}_{3}$ : Structure, ChargeCarrier Dynamics, and Photovoltaic Properties of Perovskite Solar Cells. J. Phys. Chem. C 2014, 118, 9412-9418. 
27. Song, T.-B.; Chen, Q.; Zhou, H.; Luo, S.; Yang, Y.; You, J.; Yang, Y. Unraveling Film Transformations and Device Performance of Planar Perovskite Solar Cells. Nano Energy 2015, 12, 494-500.

28. Pool, V. L.; Gold-Parker, A.; McGehee, M. D.; Toney, M. F. Chlorine in $\mathrm{PbCl}_{2}$-Derived HybridPerovskite Solar Absorbers. Chem. Mater. 2015, 27, 7240-7243.

29. Williams, S. T.; Zuo, F.; Chueh, C.-C.; Liao, C.-Y.; Liang, P.-W.; Jen, A. K. Y. Role of Chloride in the Morphological Evolution of Organo-Lead Halide Perovskite Thin Films. ACS Nano 2014, 8, 10640-10654. 30. Roldan-Carmona, C.; Gratia, P.; Zimmermann, I.; Grancini, G.; Gao, P.; Graetzel, M.; Nazeeruddin, M. K. High Efficiency Methylammonium Lead Triiodide Perovskite Solar Cells: the Relevance of NonStoichiometric Precursors. Energy Environ. Sci. 2015, 8, 3550-3556.

31. D’Innocenzo, V.; Srimath Kandada, A. R.; De Bastiani, M.; Gandini, M.; Petrozza, A. Tuning the Light Emission Properties by Band Gap Engineering in Hybrid Lead Halide Perovskite. J. Am. Chem. Soc. 2014, 136, 17730-17733.

32. De Quilettes, D. W.; Vorpahl, S. M.; Stranks, S. D.; Nagaoka, H.; Eperon, G. E.; Ziffer, M. E.; Snaith, H. J.; Ginger, D. S. Impact of Microstructure on Local Carrier Lifetime in Perovskite Solar Cells. Science 2015, 348, 683-686.

33. Dong, Q.; Fang, Y.; Shao, Y.; Mulligan, P.; Qiu, J.; Cao, L.; Huang, J. Electron-Hole Diffusion Lengths > $175 \mu \mathrm{m}$ in Solution-Grown $\mathrm{CH}_{3} \mathrm{NH}_{3} \mathrm{PbI}_{3}$ Single Crystals. Science 2015, 347, 967-970.

34. You, J.; Hong, Z.; Yang, Y.; Chen, Q.; Cai, M.; Song, T.-B.; Chen, C.-C.; Lu, S.; Liu, Y.; Zhou, H.; Yang, Y. Low-Temperature Solution-Processed Perovskite Solar Cells with High Efficiency and Flexibility. ACS Nano. 2014, 8, 1674-1680.

35. Yuan, Z.; Wu, Z.; Bai, S.; Xia, Z.; Xu, W.; Song, T.; Wu, H.; Xu, L.; Si, J.; Jin, Y.; Sun, B., Hot-Electron Injection in a Sandwiched $\mathrm{TiO}_{\mathrm{x}}-\mathrm{Au}-\mathrm{TiO}_{\mathrm{x}}$ Structure for High-Performance Planar Perovskite Solar Cells. Adv. Energy Mater. 2015, 5, 1500038.

36. Leijtens, T.; Eperon, G. E.; Pathak, S.; Abate, A.; Lee, M. M.; Snaith, H. J. Overcoming Ultraviolet Light Instability of Sensitized $\mathrm{TiO}_{2}$ with Meso-Superstructured Organometal Tri-Halide Perovskite Solar Cells. Nat. Commun. 2013, 4, 2885. 
37. Unger, E. L.; Hoke, E. T.; Bailie, C. D.; Nguyen, W. H.; Bowring, A. R.; Heumuller, T.; Christoforo, M. G.; McGehee, M. D. Hysteresis and Transient Behavior in Current-Voltage Measurements of HybridPerovskite Absorber Solar Cells. Energy Environ. Sci. 2014, 7, 3690-3698.

38. Tress, W.; Marinova, N.; Moehl, T.; Zakeeruddin, S. M.; Nazeeruddin, M. K.; Gratzel, M. Understanding the Rate-Dependent J-V Hysteresis, Slow Time Component, and Aging in $\mathrm{CH}_{3} \mathrm{NH}_{3} \mathrm{PbI}_{3}$ Perovskite Solar Cells: the Role of A Compensated Electric Field. Energy Environ. Sci. 2015, 8, 995-1004. 39. Yuan, Y.; Chae, J.; Shao, Y.; Wang, Q.; Xiao, Z.; Centrone, A.; Huang, J. Photovoltaic Switching Mechanism in Lateral Structure Hybrid Perovskite Solar Cells. Adv. Energy Mater. 2015, 5, 1500615.

40. Eames, C.; Frost, J. M.; Barnes, P. R. F.; O' Regan, B. C.; Walsh, A.; Islam, M. S. Ionic Transport in Hybrid Lead Iodide Perovskite Solar Cells. Nat. Commun. 2015, 6, 7497.

41. Shao, Y.; Xiao, Z.; Bi, C.; Yuan, Y.; Huang, J. Origin and Elimination of Photocurrent Hysteresis by Fullerene Passivation in $\mathrm{CH}_{3} \mathrm{NH}_{3} \mathrm{PbI}_{3}$ Planar Heterojunction Solar Cells. Nat. Commun. 2014, 5, 5784.

42. Li, C.; Tscheuschner, S.; Paulus, F.; Hopkinson, P. E.; Kießling, J.; Köhler, A.; Vaynzof, Y.; Huettner, S. Iodine Migration and its Effect on Hysteresis in Perovskite Solar Cells. Adv. Mater. 2016, 28, 2446-2454. 43. Xu, J.; Buin, A.; Ip, A. H.; Li, W.; Voznyy, O.; Comin, R.; Yuan, M.; Jeon, S.; Ning, Z.; McDowell, J. J.; Kanjanaboos, P.; Sun, J.-P.; Lan, X.; Quan, L. N.; Kim, D. H.; Hill, I. G.; Maksymovych, P.; Sargent, E. H. Perovskite-Fullerene Hybrid Materials Suppress Hysteresis in Planar Diodes. Nat. Commun. 2015, 6, 7081.

44. Abate, A.; Saliba, M.; Hollman, D. J.; Stranks, S. D.; Wojciechowski, K.; Avolio, R.; Grancini, G.; Petrozza, A.; Snaith, H. J. Supramolecular Halogen Bond Passivation of Organic-Inorganic Halide Perovskite Solar Cells. Nano Lett. 2014, 14, 3247-3254.

45. Noel, N. K.; Abate, A.; Stranks, S. D.; Parrott, E. S.; Burlakov, V. M.; Goriely, A.; Snaith, H. J. Enhanced Photoluminescence and Solar Cell Performance via Lewis Base Passivation of Organic-Inorganic Lead Halide Perovskites. ACS Nano. 2014, 8, 9815-9821. 
46. Li, X.; Bi, D.; Yi, C.; Décoppet, J.-D.; Luo, J.; Zakeeruddin, S. M.; Hagfeldt, A.; Grätzel, M. A Vacuum Flash-Assisted Solution Process for High-Efficiency Large-Area Perovskite Solar Cells. Science 2016. 353, $58-62$.

47. Lee, M. M.; Teuscher, J.; Miyasaka, T.; Murakami, T. N.; Snaith, H. J. Efficient Hybrid Solar Cells based on Meso-Superstructured Organometal Halide Perovskites. Science 2012, 338, 643-647.

48. Docampo, P.; Ball, J. M.; Darwich, M.; Eperon, G. E.; Snaith, H. J. Efficient Organometal Trihalide Perovskite Planar-Heterojunction Solar Cells on Flexible Polymer Substrates. Nat. Commun. 2013, 4, 2761. 49. Liu, D.; Kelly, T. L. Perovskite Solar Cells with A Planar Heterojunction Structure Prepared Using Room-Temperature Solution Processing Techniques. Nat. Photonics. 2014, 8, 133-138.

50. Yang, Y.; Feng, S.; Li, M.; Wu, Z.; Fang, X.; Wang, F.; Geng, D.; Yang, T.; Li, X.; Sun, B.; Gao, X. Structure, Optical Absorption, and Performance of Organic Solar Cells Improved by Gold Nanoparticles in Buffer Layers. ACS Appl. Mater. Interfaces. 2015, 7, 24430-24437. 


\section{Images and Tables}

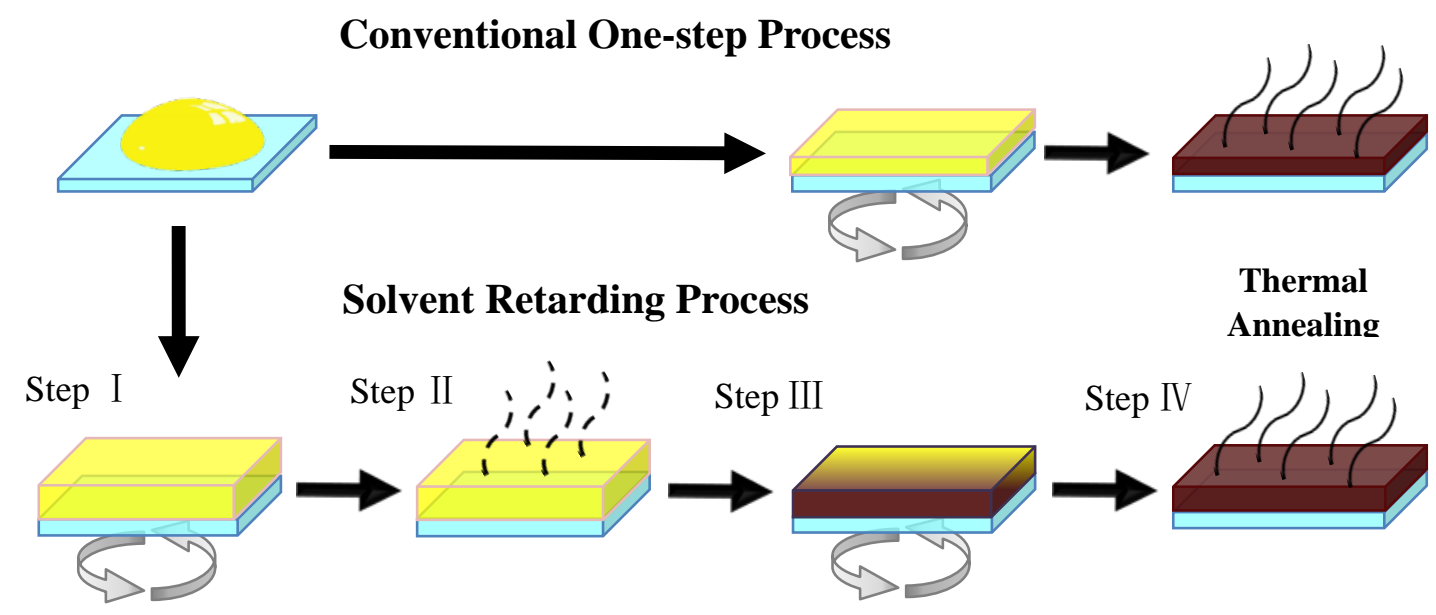

Figure 1 Perovskite film deposition via the conventional one-step process (above) and the SR process (below). 

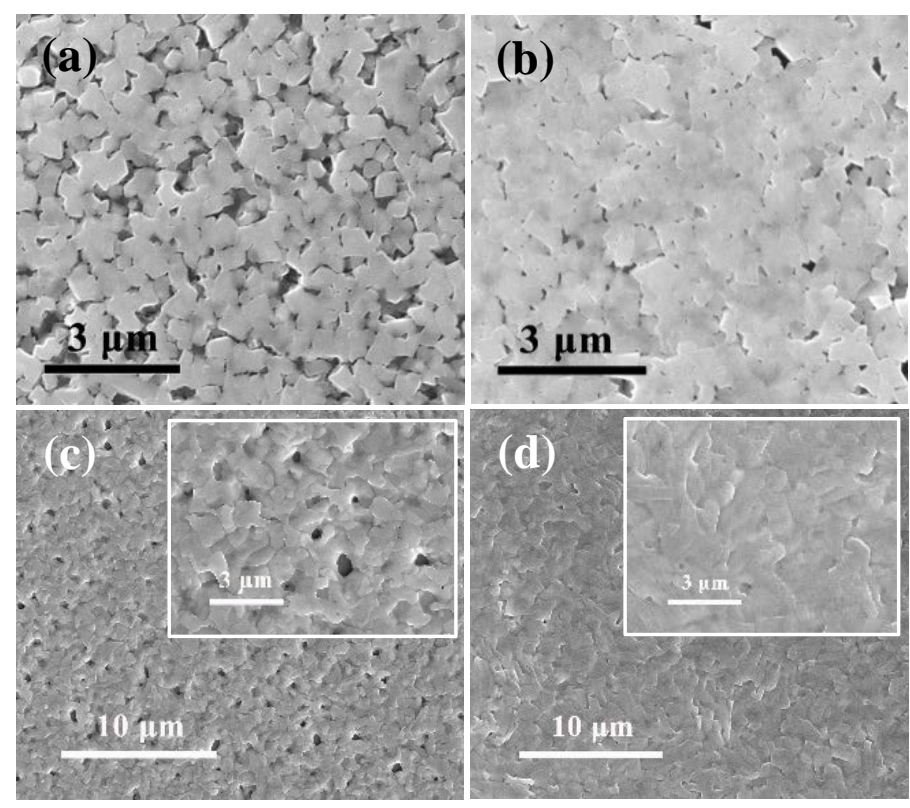

Figure 2 SEM images of precursor film before thermal annealing process: a) Con film, b) 30 s SR film and after thermal annealing process: c) Con film, d) 30 s SR film (the scale bars are $10 \mu \mathrm{m}$; the inset images are high resolution SEM images of corresponding perovskite films, the scale bars are $3 \mu \mathrm{m}$ ). 


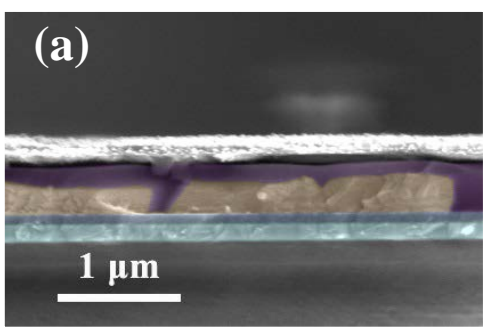

Ag Electrode
Spiro-OMeTAD
Perovskite
ITO/TiOx
Glass
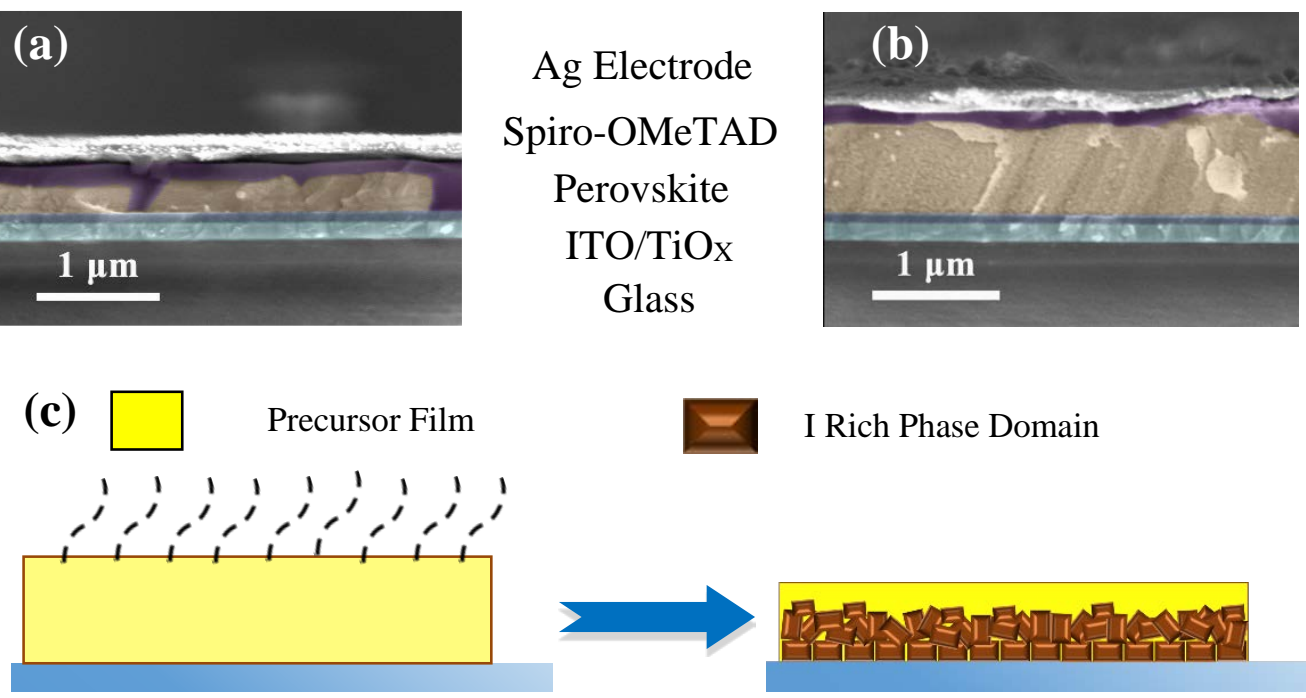

Step II

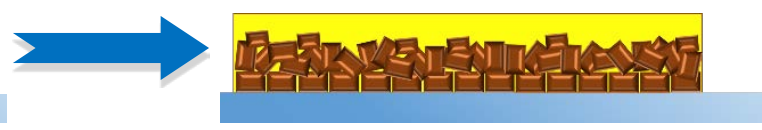

Step III
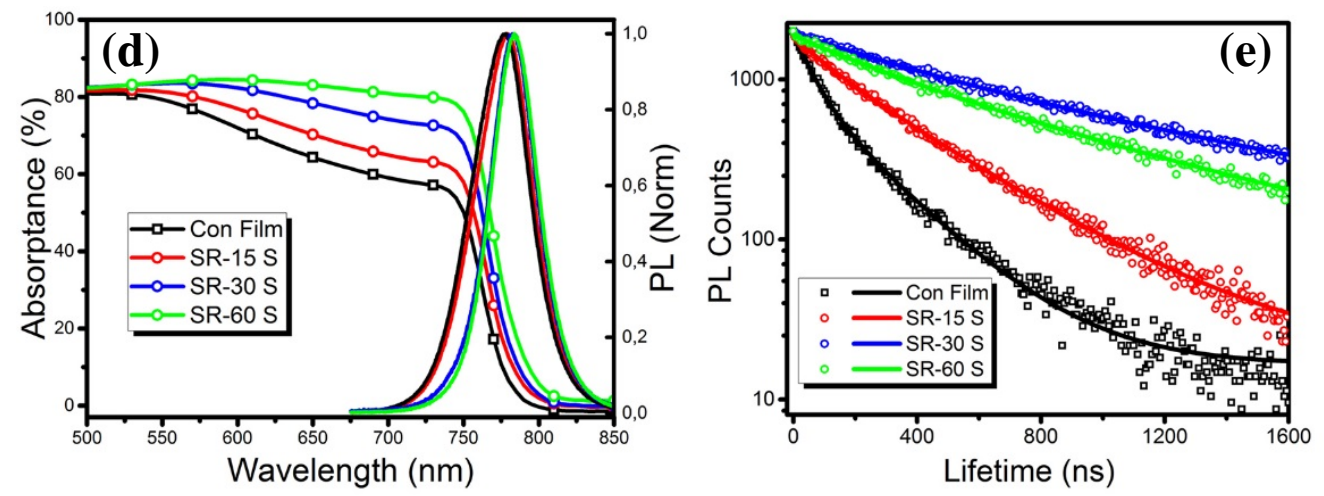

Figure 3 Cross-sectional SEM image of perovskite devices fabricated with: a) Con film, b) 30 s SR film; c) Schematic image of I rich components domain formation in the precursor film during SR process; d) UVvis absorption spectra and steady state PL spectra of Con and SR films after annealing process; e) Timecorrelated single-photon counting (TCSPC) results of perovskite films processed with different conditions. 

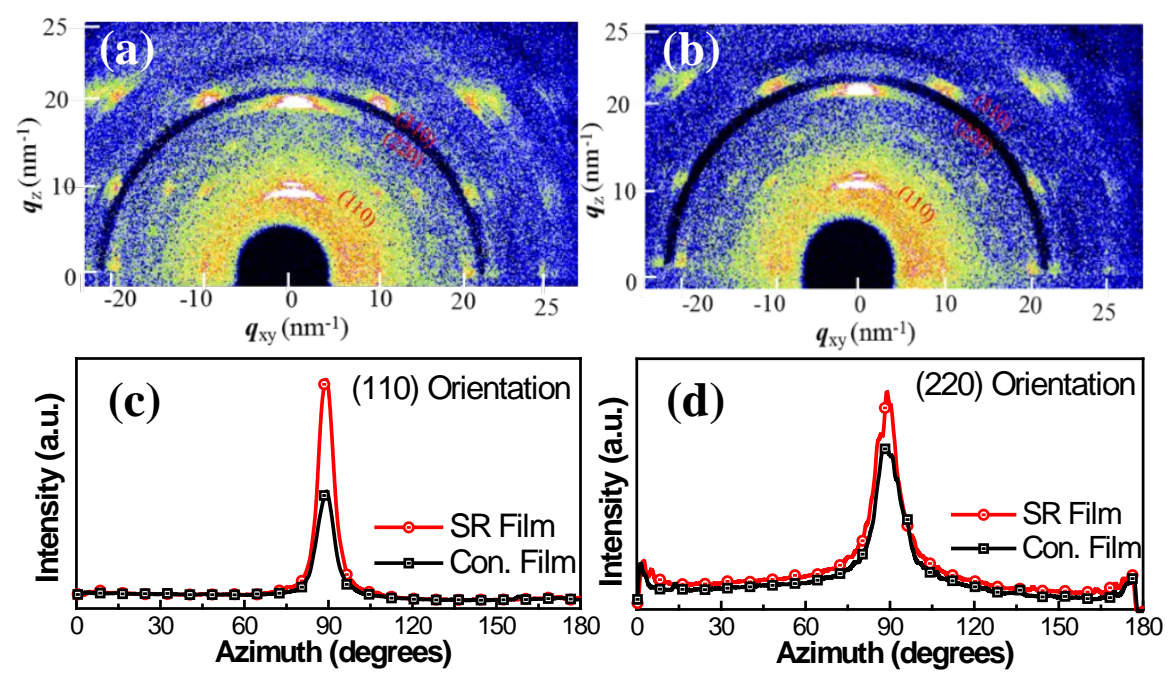

Figure 4 2D GIXRD patterns of the perovskite films prepared via the conventional process and the $30 \mathrm{~s}$ SR process in (a) and (b), respectively; The integrated intensity plots along the diffraction rings associated with the c) (110) planes and d) (220) planes of $\mathrm{CH}_{3} \mathrm{NH}_{3} \mathrm{PbI}_{3-\mathrm{x}} \mathrm{Cl}_{\mathrm{x}}$ in Con film and $30 \mathrm{~s}$ SR processed one. 

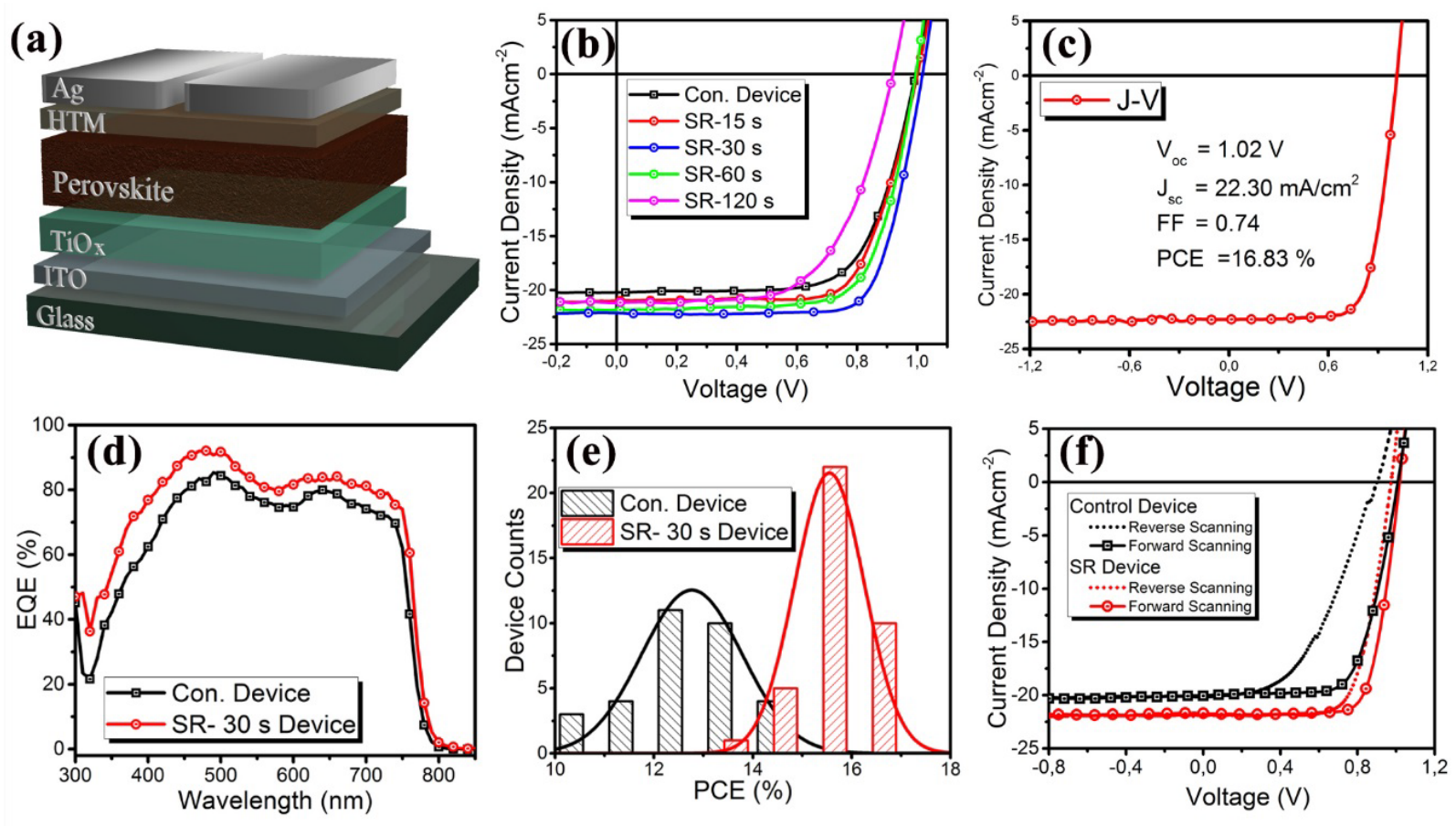

Figure 5 a) Schematic illustration of device configuration (ITO/TiO $/ \mathrm{CH}_{3} \mathrm{NH}_{3} \mathrm{PbI}_{(3-\mathrm{x})} \mathrm{Cl}_{\mathrm{x}} / \mathrm{Sp}$ iroOMeTAD/Ag electrode); b) J-V curves of device based on Con film and different SR time processed films; c) J-V curve of the champion device; d) EQE spectra of device; e) PCE histogram of devices fabricated with conventional method and 30 s SR process; f) J-V curves obtained with different scanning voltage orientation of devices based on conventional prepared perovskite film and $30 \mathrm{~s}$ SR processed one. The scanning rate is $100 \mathrm{mV} / \mathrm{s}$. 
Table 1 Photovoltaic parameters of the devices with different fabrication conditions, all the data were extracted from J-V measurements.

\begin{tabular}{ccccc}
\hline SR Time & $\mathbf{V}_{\text {oc }}(\mathbf{V})$ & $\mathbf{J}_{\mathrm{sc}}\left(\mathbf{m A} \cdot \mathbf{c m}^{-2}\right)$ & Fill Factor & PCE (\%) \\
\hline \multirow{2}{*}{ Control (0 s) } & $1.01^{\mathrm{a}}$ & 20.02 & 0.68 & 13.75 \\
& $(1.00 \pm 0.02)^{\mathrm{b}}$ & $(19.84 \pm 0.79)$ & $(0.66 \pm 0.03)$ & $(12.89 \pm 0.95)$ \\
$\mathbf{1 5} \mathrm{s}$ & 1.01 & 21.02 & 0.70 & 14.91 \\
& $(1.01 \pm 0.01)$ & $(20.87 \pm 0.40)$ & $(0.69 \pm 0.02)$ & $(14.45 \pm 0.38)$ \\
$\mathbf{3 0 ~ s}$ & 1.03 & 22.11 & 0.73 & $(16.63$ \\
& $(1.02 \pm 0.02)$ & $(22.04 \pm 0.33)$ & $(0.72 \pm 0.02)$ & 15.51 \\
$\mathbf{6 0 ~ s}$ & 1.00 & 21.85 & 0.71 & $(15.22 \pm 0.21)$ \\
& $(1.00 \pm 0.02)$ & $(21.50 \pm 0.24)$ & $(0.70 \pm 0.01)$ & 12,02 \\
\hline
\end{tabular}

Table statement: $\left.{ }^{\mathrm{a}}\right]$ representative device electric parameters, $\left.{ }^{\mathrm{b}}\right]$ averaged device parameters with at least 12 devices. 


\section{Table of Contents Graphic}

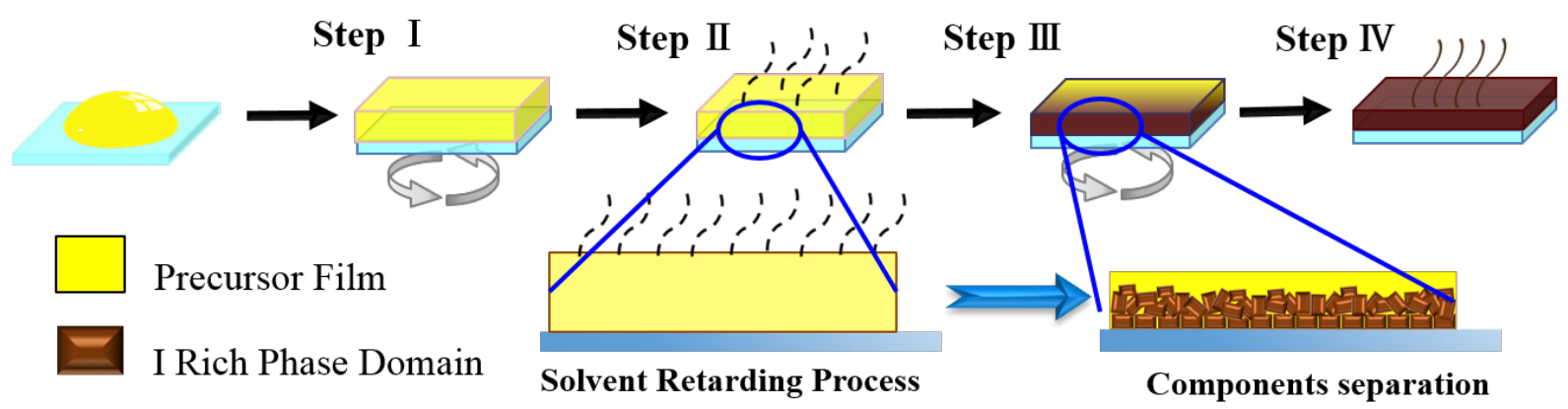




\title{
Supporting Information
}

\section{>800-nm-Thick Pinhole-Free Perovskite Films via Facile Solvent Retarding Process for Efficient Planar Solar Cells}

\author{
Zhongcheng Yuan ${ }^{\dagger \neq}$, Yingguo Yang ${ }^{\S}$, Zhongwei $\mathrm{Wu}^{\dagger}$, Sai $\mathrm{Bai}^{\ddagger}$, Weidong $\mathrm{Xu}^{\dagger}$, Tao Song ${ }^{\dagger}$,

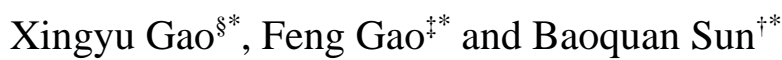

${ }^{\dagger}$ Jiangsu Key Laboratory for Carbon-Based Functional Materials \& Devices, Institute of Functional Nano \& Soft Materials (FUNSOM), Soochow University, Suzhou, 215123, China

${ }^{\ddagger}$ Department of Physics, Chemistry and Biology (IFM), Linköping University, Linköping, SE-58183 Sweden

$\S$ Shanghai Synchrotron Radiation Facility (SSRF), Shanghai Institute of Applied Physics, Key Laboratory of Interfacial Physics and Technology, Shanghai Institute of Applied Physics, Chinese Academy of Sciences, Shanghai, 201800, China

Corresponding Authors: bqsun@suda.edu.cn; fenga@ifm.liu.se; gaoxingyu@sinap.ac 

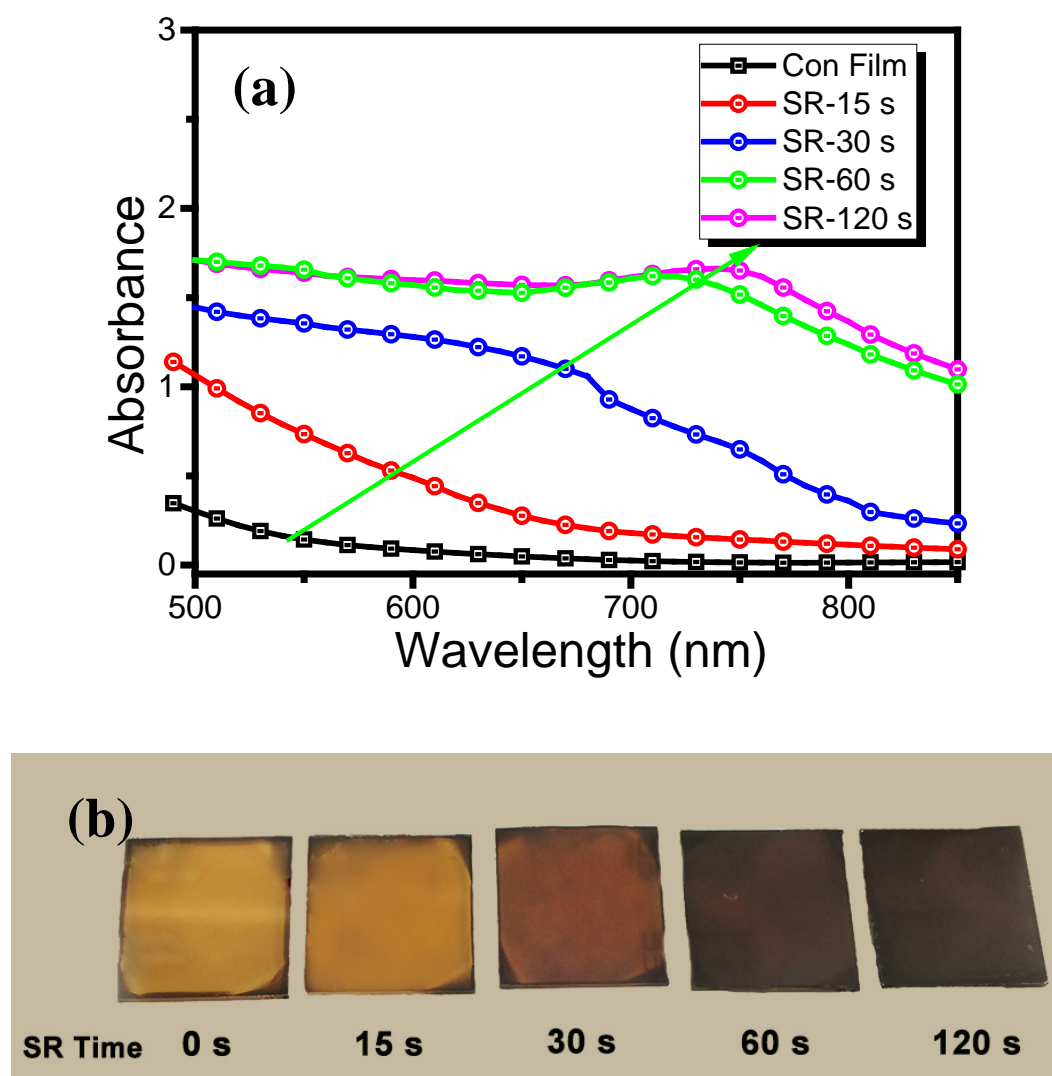

Figure S1 a) UV-vis absorption spectra of as-deposited precursor film with different SR time; b) the image of the precursor films (from left to right: Con film and 15 s, 30 s, 60 s, 120 s SR processed films. 


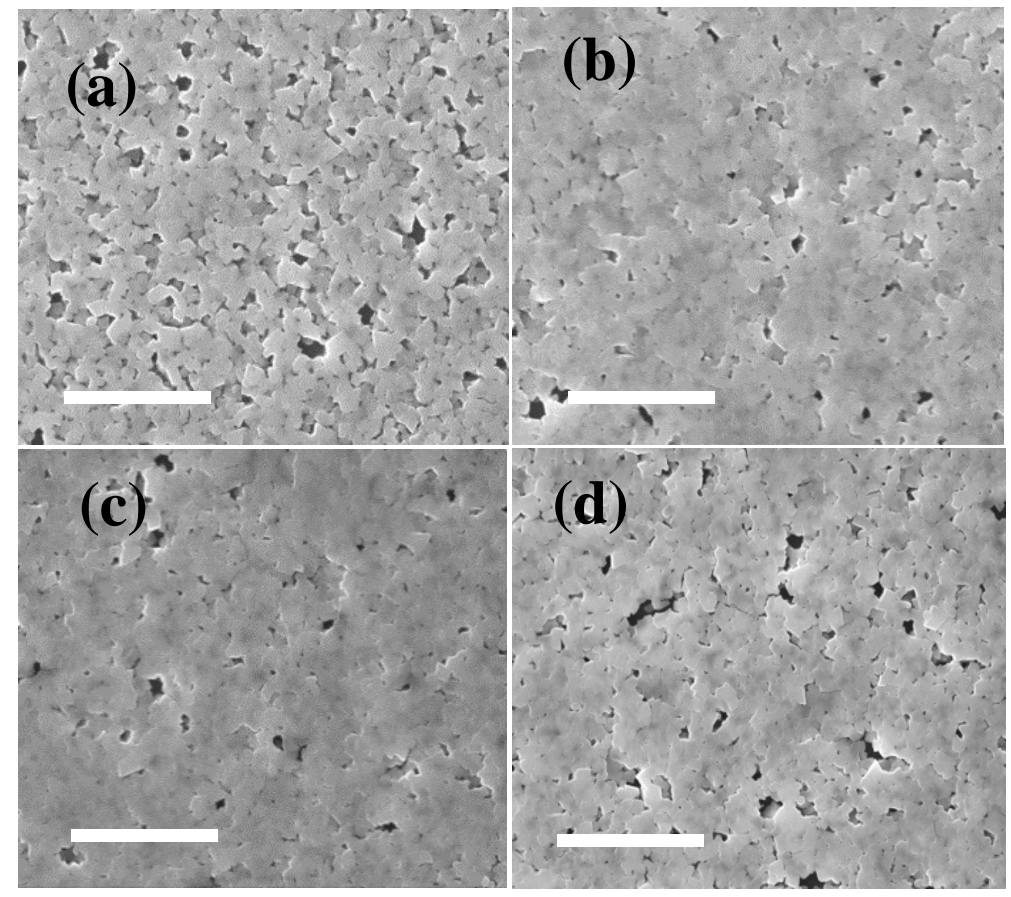

Figure S2 SEM images of perovskite precursor film with different SR time: a) 15 s, b) 30 s, c) $60 \mathrm{~s}$ and d) $120 \mathrm{~s}$. All scale bars are $5 \mu \mathrm{m}$. 


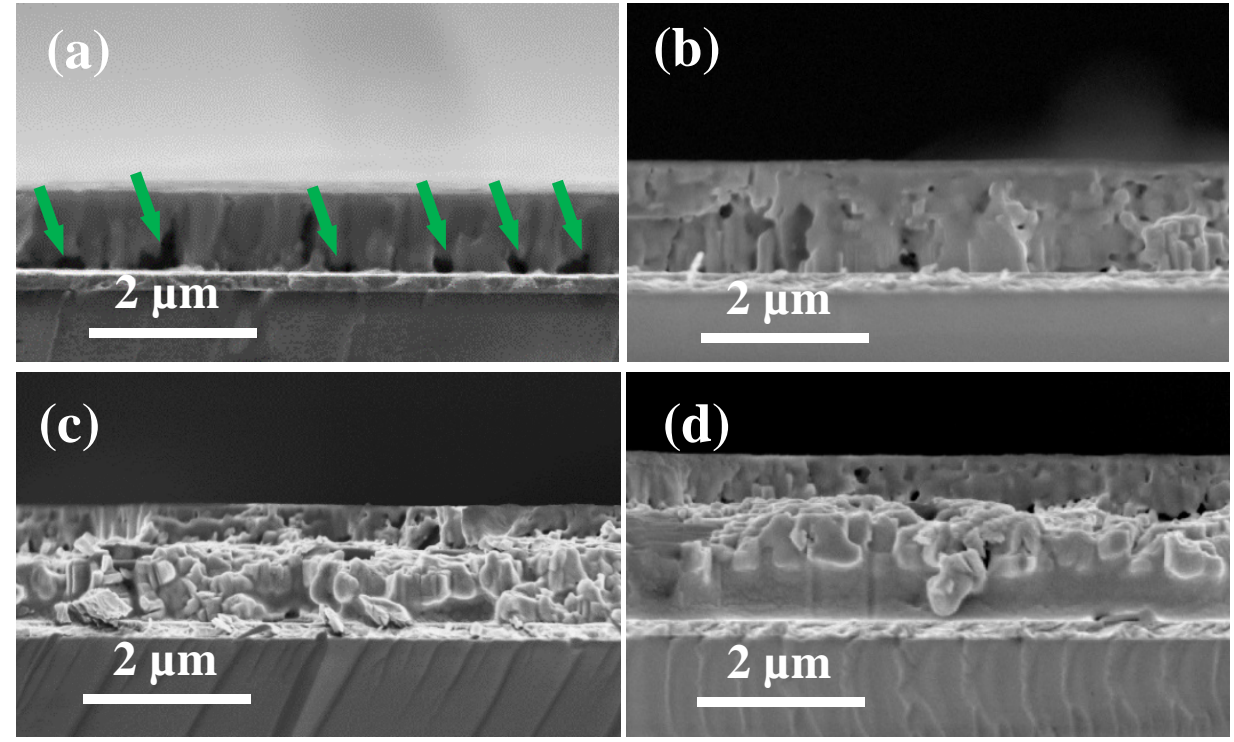

Figure S3 Cross-sectional SEM image of precursor films: a) Con film, b) 15 s, c) 30 s and d) $60 \mathrm{~s}$ SR film. The pinholes formed at the interface were indicated by the green arrows in Figure (a). 

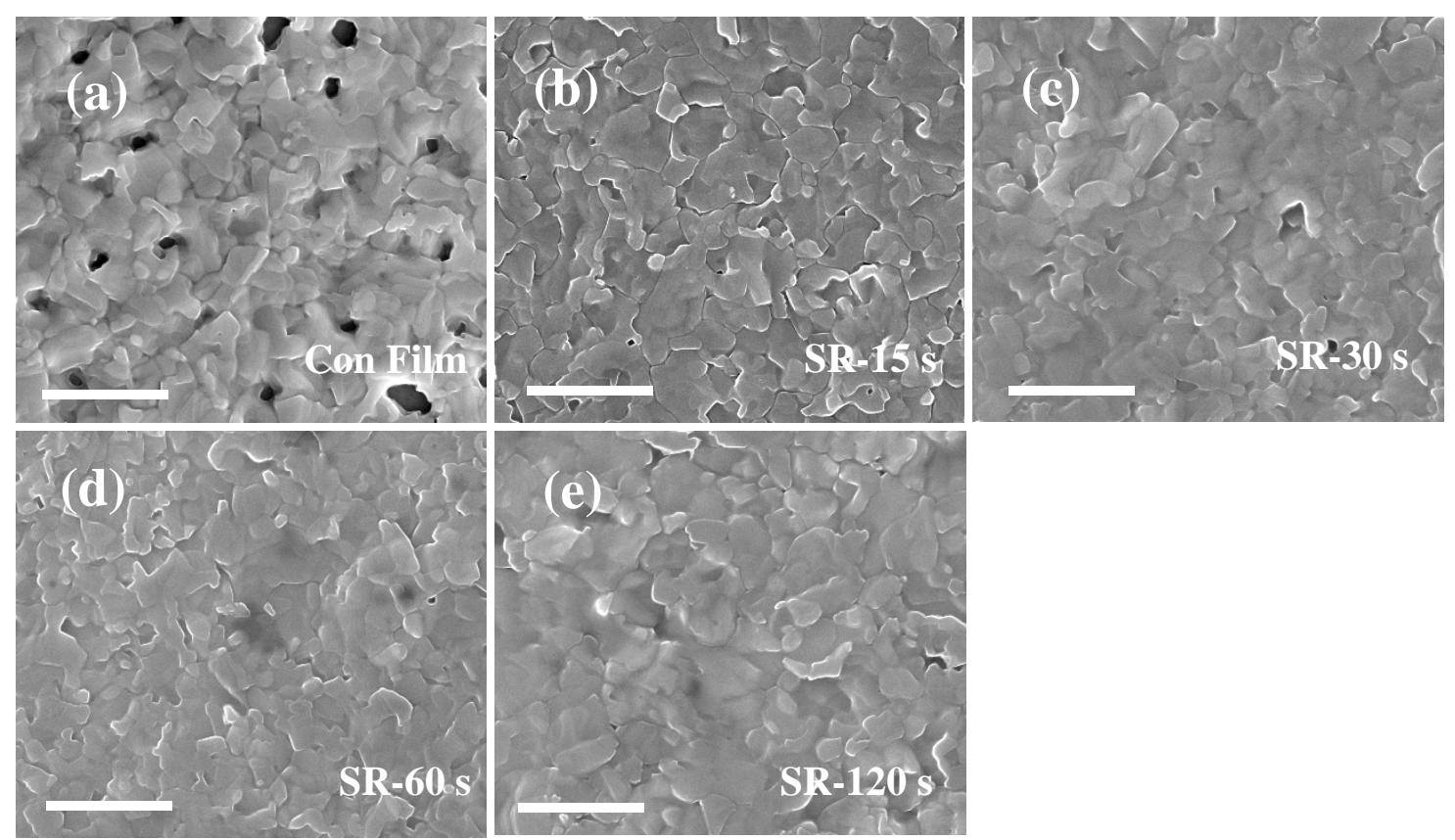

Figure S4 a) Top view SEM images of conventional prepared perovskite film; SEM images of perovskite film deposited with different SR time: b) $15 \mathrm{~s}$, c) $30 \mathrm{~s}$, d) $60 \mathrm{~s}$, e) $120 \mathrm{~s}$. The scale bars for images (a-e) are $3 \mu \mathrm{m}$. 

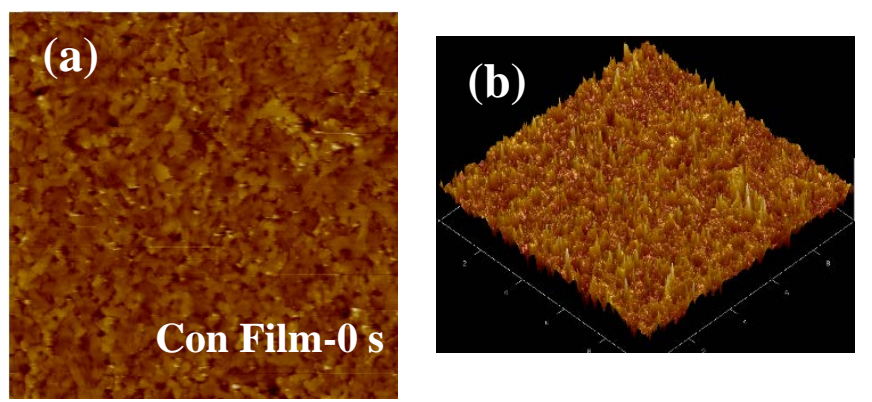

$200 \mathrm{~nm}$
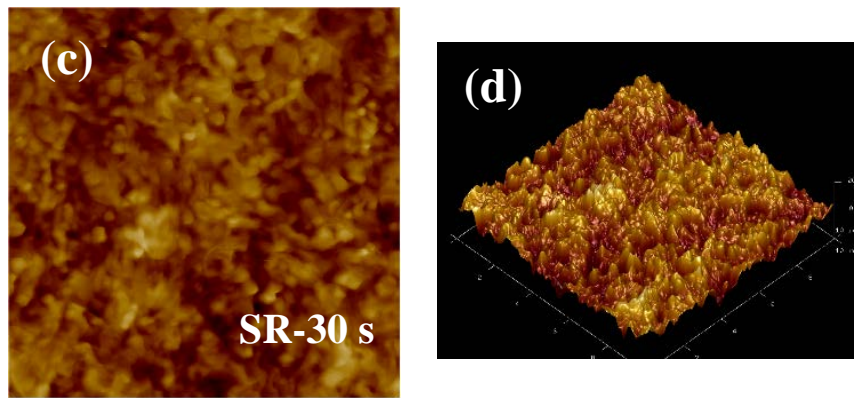

$-200 \mathrm{~nm}$
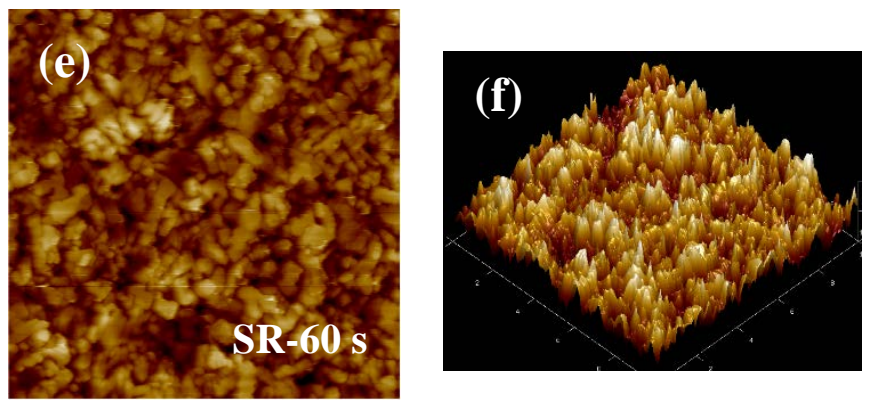

$200 \mathrm{~nm}$
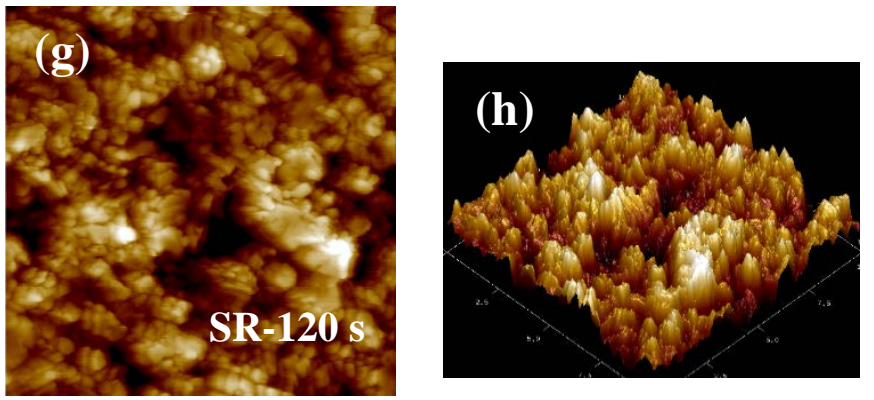

$200 \mathrm{~nm}$

$-200 \mathrm{~nm}$

$-200 \mathrm{~nm}$

$200 \mathrm{~nm}$

$-200 \mathrm{~nm}$

Figure S5 AFM images of conventional prepared perovskite film: a) height image, b) 3D image.

AFM height images and 3D images of perovskite films deposited with different SR time: c) and

d) $30 \mathrm{~s}$; e) and f) $60 \mathrm{~s}$; g) and h) $120 \mathrm{~s}$. The sizes of height images are all $10 \mu \mathrm{m} \times 10 \mu \mathrm{m}$. 


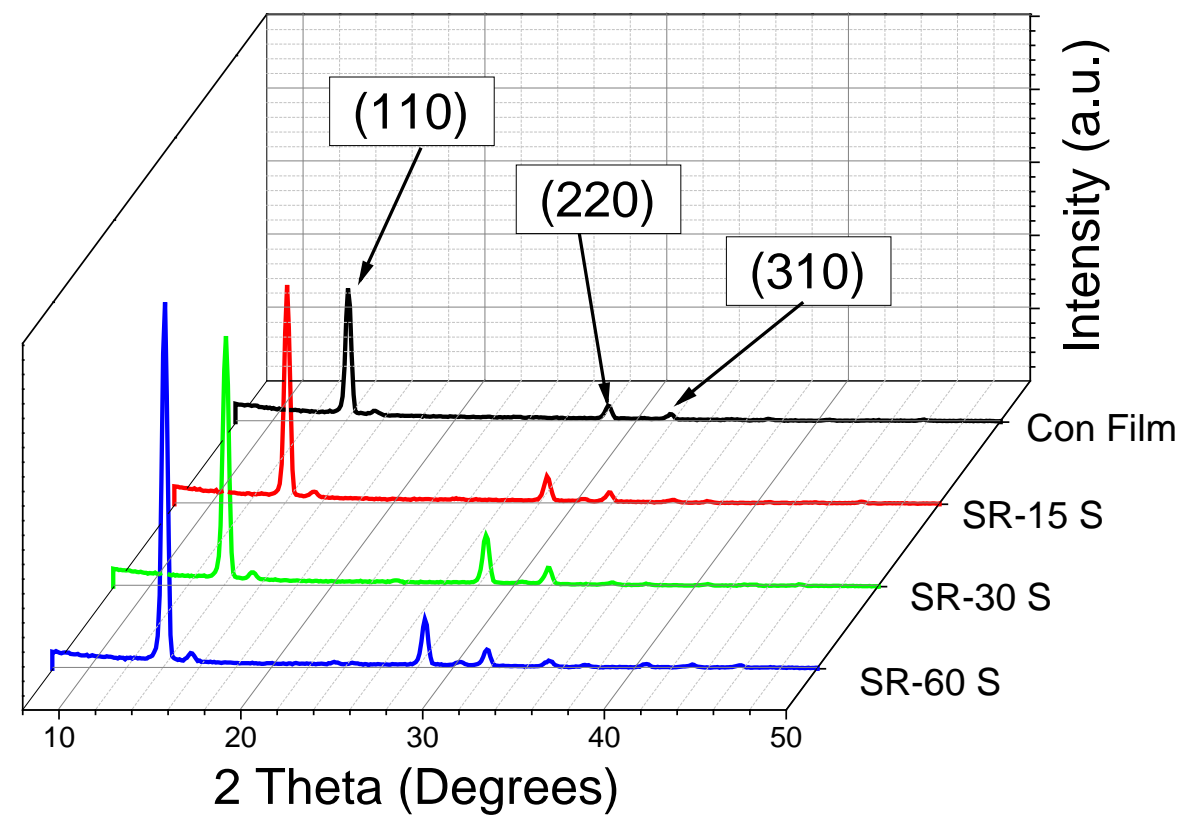

Figure S6 XRD spectra of perovskite film prepared with conventional method and different SR time. 

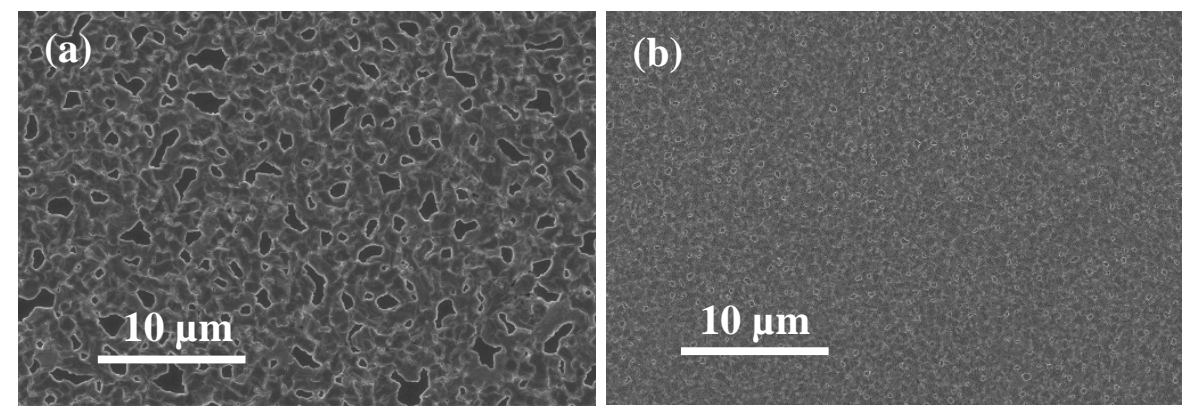

Figure S7 a) Top-view SEM images of perovskite films prepared with wet chemistry solvent annealing process. The film was deposited by spin-coating the precursor solution on $\mathrm{TiO}_{\mathrm{x}}$ substrate for $3 \mathrm{~s}$ and then left it to dry naturally in the glass petri dish in nitrogen atmosphere. Then anneal the sample at $100^{\circ} \mathrm{C}$ until the color of film was fully changed to brown ( $\left.20 \mathrm{~min}\right)$. b) Top-view SEM images of perovskite films prepared with conventional thermal annealing process. The film was obtained by spin coating the precursor film for $45 \mathrm{~s}$ and annealing the film directly on hot plate at $100{ }^{\circ} \mathrm{C}$ for $\sim 30 \mathrm{~min}$. 


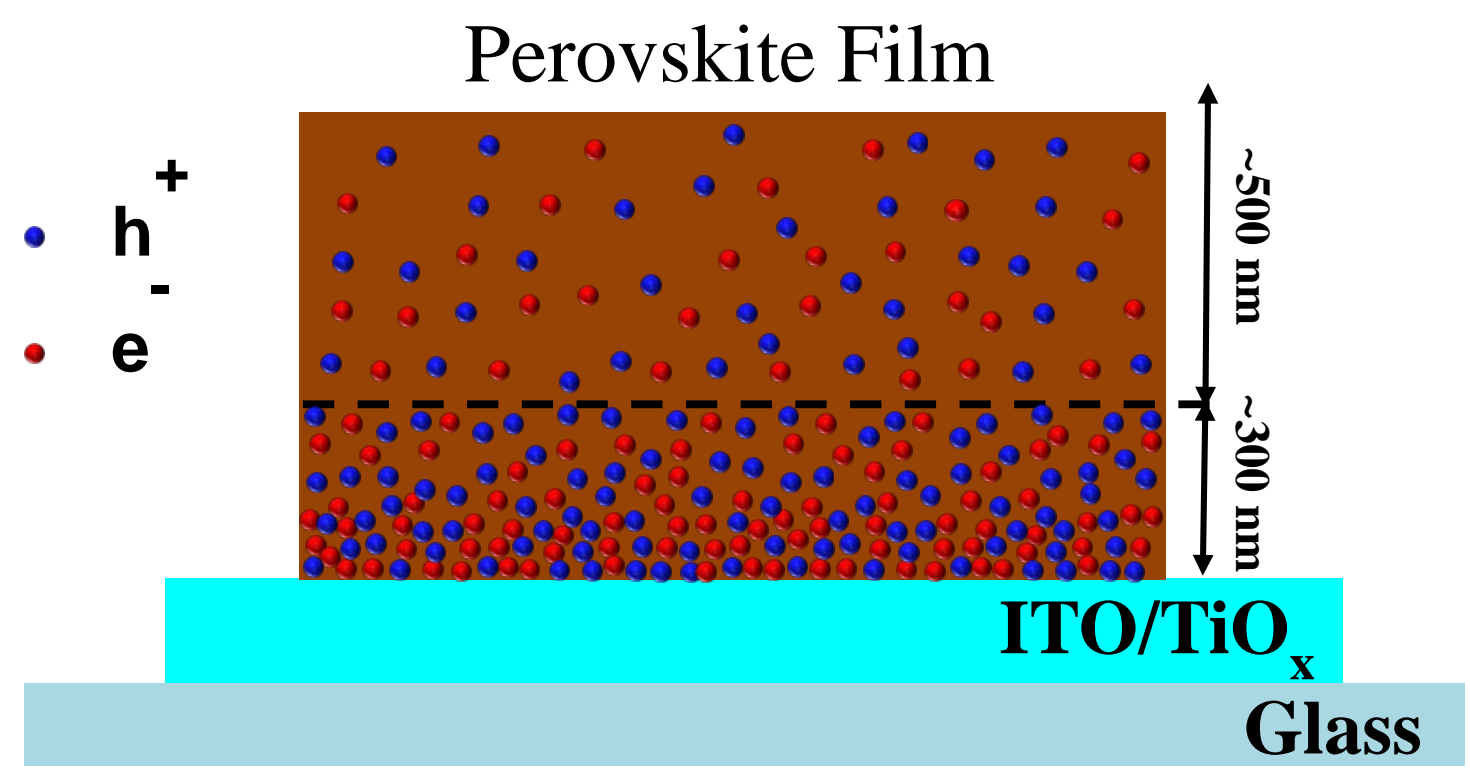

Figure S8 Distribution of charge carriers generated by the photon excitons within the perovskite film. 


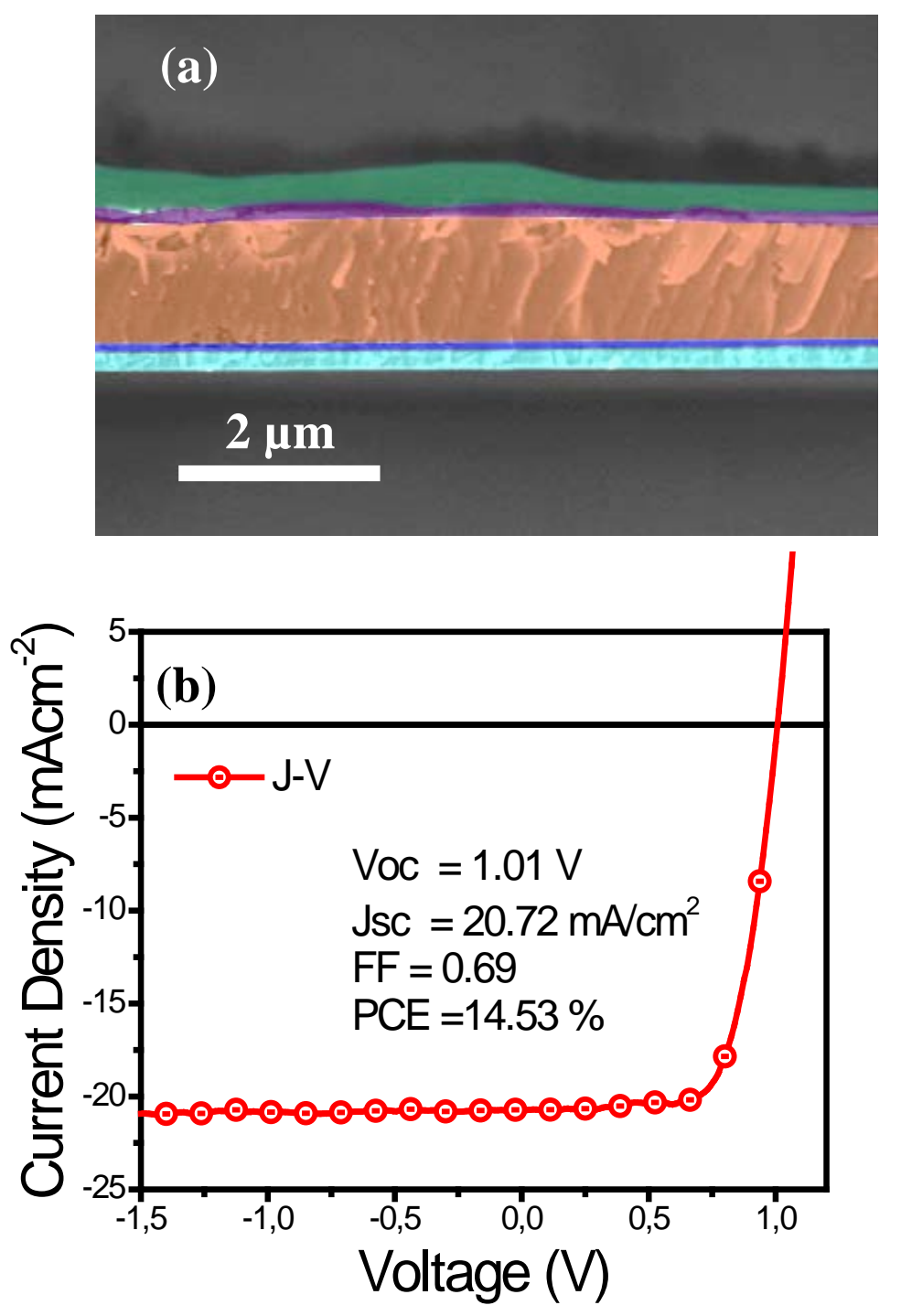

Figure S9 a) Cross-sectional SEM images of device based on perovskite film with $1200 \mathrm{~nm}$ thickness (film was prepared with $50 \mathrm{wt} \%$ precursor solution and $30 \mathrm{~s}$ SR time); b) device J-V curve. 
Table S1: Average roughness value of films prepared with different SR process time.

\begin{tabular}{ccccc}
\hline SR Time (s) & 0 & 30 & 60 & 120 \\
& & & & \\
\hline Average Roughness (nm) & 26.8 & 36.2 & 47.9 & 79.1 \\
\hline
\end{tabular}

Table S2: TCSPC characterization results of the perovskite films processed with different condition.

\begin{tabular}{cccccc}
\hline Samples & $\boldsymbol{\tau}_{\mathbf{1}} \mathbf{( n )}$ & $\begin{array}{c}\text { Fraction 1 } \\
\mathbf{( \% )}\end{array}$ & $\boldsymbol{\tau}$ 2 (ns) & $\begin{array}{c}\text { Fraction 2 } \\
\mathbf{( \% )}\end{array}$ & $\begin{array}{c}\text { Averaged } \boldsymbol{\tau} \\
\text { (ns) }\end{array}$ \\
\hline Conn film & 60.3 & 55.8 & 228.6 & 45.2 & 134.5 \\
SR-15 s & 119.6 & 23.4 & 359.0 & 76.6 & 303.0 \\
SR-30 s & 377.5 & 34.9 & 1083.5 & 65.1 & 837.3 \\
SR-60 s & 249.3 & 24.8 & 730.1 & 75.2 & 610.8 \\
\hline
\end{tabular}


Table S3: Photovoltaic parameters of perovskite devices based on films with thicknesses over $500 \mathrm{~nm}$ in literature.

\begin{tabular}{|c|c|c|c|c|c|c|}
\hline Device Configuration & $\begin{array}{l}\text { Thickness } \\
\text { (nm) }\end{array}$ & $\begin{array}{l}\text { Voc } \\
\text { (V) }\end{array}$ & $\begin{array}{c}\text { JsC } \\
\left(\mathrm{mAcm}^{-}\right. \\
\text {2) }\end{array}$ & FF (\%) & PCE (\%) & Ref \\
\hline $\mathrm{ITO} / \mathrm{HTM} / \mathrm{MAPbI}_{3} / \mathrm{PCBM} / \mathrm{C}_{60} / \mathrm{BCP} / \mathrm{Al}$ & $\sim 600$ & 1.06 & 22.2 & 73.4 & 17.2 & 1 \\
\hline 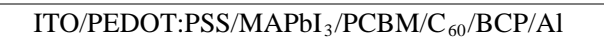 & $\sim 1000$ & 0.95 & 20.5 & 74.3 & 14.8 & 2 \\
\hline ITO/PEDOT:PSS/MAPbI $/{ }_{3} / \mathrm{PCBM} / \mathrm{C}_{60} / \mathrm{BCP} / \mathrm{Al}$ & $\sim 630$ & 0.96 & 21.0 & 76.0 & 15.6 & 2 \\
\hline ITO/PEDOT:PSS/MAPbI $/{ }_{3} / \mathrm{PCBM} / \mathrm{C}_{60} / \mathrm{BCP} / \mathrm{Al}$ & $\sim 3000$ & $\sim 0.88$ & $\sim 20.0$ & $\sim 63.0$ & $\sim 12.8 \%$ & 3 \\
\hline FTO/mesoporous $\mathrm{TiO}_{2} / \mathrm{FAPbI}_{3} / \mathrm{PTAA} / \mathrm{Au}$ & $\sim 560$ & 1.06 & 24.7 & 77.5 & 20.2 & 4 \\
\hline $\begin{array}{c}\mathrm{FTO} / \text { mesoporous } \mathrm{TiO}_{2} / \mathrm{Cs}_{\mathrm{x}}\left(\mathrm{MA}_{0.17} \mathrm{FA}_{0.83}\right)_{(100-} \\
{ }_{\mathrm{x})} \mathrm{Pb}\left(\mathrm{I}_{0.83} \mathrm{Br}_{0.17}\right)_{3} / \text { Spiro-OMeTAD/Au }\end{array}$ & $\sim 500$ & 1.13 & 22.69 & 74.8 & 19.2 & 5 \\
\hline 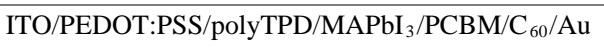 & $\sim 900$ & 0.94 & 19.5 & 65.0 & 12.0 & 6 \\
\hline $\begin{array}{c}\text { ITO/compact } \mathrm{TiO}_{2} / \mathrm{MAPbI}_{3-\mathrm{x}} \mathrm{Cl}_{\mathrm{x}} / \text { Spiro- } \\
\text { OMeTAD/Ag }\end{array}$ & $\sim 800$ & 1.02 & 22.30 & 74.0 & 16.83 & Present \\
\hline
\end{tabular}

Table S4: J-V statistics of the devices with different condition scanned with different direction with bias step of $100 \mathrm{mV}$.

\begin{tabular}{ccccccc}
\hline Sample & scanning & $\mathbf{V}_{\text {oc }}(\mathbf{V})$ & $\mathbf{J}_{\text {sc }}\left(\mathbf{m A} \cdot \mathbf{c m}^{-2}\right)$ & Fill Factor & PCE (\%) & Difference (\%) \\
\hline Conventional & forward & 1.01 & 19.46 & 0.68 & 13.39 & 60.7 \\
device & reverse & 0.90 & 19.55 & 0.47 & 8.33 & 16.06 \\
30 s SR process & forward & 1.02 & 22.18 & 0.71 & 14.73 & 9.03 \\
device & reverse & 0.97 & 22.02 & 0.69 & \\
\hline
\end{tabular}




\section{Reference}

1. Bi, C.; Wang, Q.; Shao, Y.; Yuan, Y.; Xiao, Z.; Huang, J. Non-Wetting Surface-Driven High-AspectRatio Crystalline Grain Growth for Efficient Hybrid Perovskite Solar Cells. Nature commun. 2015, 6. 7747.

2. Xiao, Z.; Dong, Q.; Bi, C.; Shao, Y.; Yuan, Y.; Huang, J. Solvent Annealing of Perovskite-Induced Crystal Growth for Photovoltaic-Device Efficiency Enhancement. Adv. Mater. 2014, 26, 6503-6509.

3. Deng, Y.; Peng, E.; Shao, Y.; Xiao, Z.; Dong, Q.; Huang, J. Scalable fabrication of Efficient Organolead Trihalide Perovskite Solar Cells with Doctor-Bladed Active Layers. Energy Environ. Sci. 2015, 8, 1544-1550.

4. Yang, W. S.; Noh, J. H.; Jeon, N. J.; Kim, Y. C.; Ryu, S.; Seo, J.; Seok, S. I. High-Performance Photovoltaic Perovskite Layers Fabricated through Intramolecular Exchange. Science 2015, 348, 12341237.

5. Saliba, M.; Matsui, T.; Seo, J.-Y.; Domanski, K.; Correa-Baena, J.-P.; Nazeeruddin, M. K.; Zakeeruddin, S. M.; Tress, W.; Abate, A.; Hagfeldt, A. Cesium-Containing Triple Cation Perovskite Solar Cells: Improved Stability, Reproducibility and High Efficiency. Energy Environ. Sci. 2016, 9, 1989-1997.

6. Momblona, C.; Malinkiewicz, O.; Roldán-Carmona, C.; Soriano, A.; Gil-Escrig, L.; Bandiello, E.; Scheepers, M.; Edri, E.; Bolink, H. J. Efficient Methylammonium Lead Iodide Perovskite Solar Cells With Active Layers From 300 to 900 nm. APL Mater. 2014, 2, 081504. 